\title{
Trends in 3D Printing Processes for Biomedical Field: Opportunities and Challenges
}

\author{
Alina Ghilan ${ }^{1} \cdot$ Aurica P. Chiriac ${ }^{1}$ (D) - Loredana E. Nita ${ }^{1} \cdot$ Alina G. Rusu $^{1} \cdot$ Iordana Neamtu ${ }^{1} \cdot$ Vlad Mihai Chiriac $^{2}$
}

Published online: 31 March 2020

○ Springer Science+Business Media, LLC, part of Springer Nature 2020

\begin{abstract}
Additive manufacturing (AM) is considered the latest technology that creates breakthrough innovations and addresses complex medical problems. This is clearly demonstrated by the promising results obtained in regenerative medicine, diagnosis, implants, artificial tissues and organs. This paper provides a basic understanding of the fundamentals of 3D/4D printing along with bioprinting processes. We are briefly discussing about the main printing systems including stereolithography, inkjet 3D printing, extrusion, laser-assisted printing, selective laser melting and Poly-Jet printing. The basic requirements for the selection of successful inks based on polymers, polymer blends, and composites are described. Furthermore, the on-going transition from 3D to 4D printing is highlighted with emphasis on the newest applications in the medical area. Also, a glimpse into the future possibilities and benefits provided by machine learning in the additive manufacturing field is emphasized. Machine learning can improve printing efficiency by using generative design and testing in the pre-fabrication stage. Finally, important limitations and prospects are identified. Within the next few years, AM is set to become an important component in patient-specific medical technologies.
\end{abstract}

\section{Graphic Abstract}

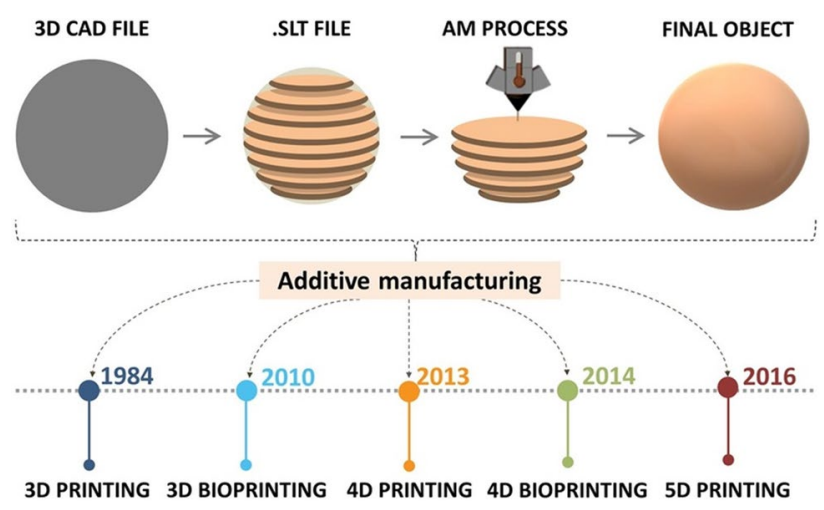

Keywords Additive manufacturing $\cdot$ Medicine $\cdot$ Machine learning $\cdot$ Biomaterials $\cdot$ Bioprinting $\cdot$ Polymer $\cdot$ Bioinks

Aurica P. Chiriac

achiriac@icmpp.ro; achiriac1@yahoo.com

1 "Petru Poni" Institute of Macromolecular Chemistry, Laboratory of Inorganic Polymers, 41-A Grigore Ghica Voda Alley, Iasi 700487, Romania

2 "Gh. Asachi" Technical University, Faculty of Electronics, Telecommunications and Information Technology, Bd. Carol I, 11A, Iasi 700506, Romania

\section{Abbreviations}

ABS

RGD

A.I

AM

$\mathrm{CA}$

CAD

CMC

DA
Acrylonitrile butadiene styrene Arginine-glycine aspartater Artificial intelligence Additive manufacturing Citric acid Computer-aided design Carboxymethyl cellulose Diacrylate 


\begin{tabular}{|c|c|}
\hline DIW & Direct-ink writing \\
\hline DLP & Digital light projection \\
\hline EHD & Electro-hydrodynamic \\
\hline FDA & Food and Drug Administration \\
\hline FDM & Fused deposition modeling \\
\hline HA & Hyaluronic acid \\
\hline hADSCs & Human adipose-derived stem cells \\
\hline hMSCs & Mesenchymal stem cells \\
\hline LCST & Lower critical solution temperature \\
\hline MGI & Materials Genome Initiative \\
\hline ML & Machine learning \\
\hline MN & Micro-needles \\
\hline ECM & Native extracellular matrix \\
\hline PA & Poly(acrylamide) \\
\hline $\mathrm{PC}$ & Poly(carbonate) \\
\hline PCL & Poly(caprolactone) \\
\hline PCL-PEG-PCL & $\begin{array}{l}\text { Poly(caprolactone)-Poly(ethylene } \\
\text { glycol)-Poly(caprolactone) }\end{array}$ \\
\hline PCLDMA & Poly(caprolactone dimethacrylate) \\
\hline PDA & Poly(dopamine) \\
\hline PDMS & Poly(dimethylsiloxane) \\
\hline PEG & Poly(ethylene glycol) \\
\hline PEI & Poly(ethyleneimine) \\
\hline PGA & Poly(glycolic acid) \\
\hline PLA & Poly(lactic acid) \\
\hline PVA & Poly(vinyl alcohol) \\
\hline PVAc & Poly(vinyl acetate) \\
\hline pNIPAM & Poly(N-isopropylacrylamide) \\
\hline PVP & Poly(vinylpyrrolidone) \\
\hline PU & Poly(urethane) \\
\hline QSARs & Structure-activity relationships \\
\hline RGD & Arginine-glycine-aspartate \\
\hline SBF & Simulated body fluid \\
\hline SMP & $\begin{array}{l}\text { Shape memory thermoplastics } \\
\text { polymers }\end{array}$ \\
\hline $\mathrm{Tm}$ & Melting temperature \\
\hline TMSC & $\begin{array}{l}\text { Human tonsil-derived mesenchymal } \\
\text { stem cells }\end{array}$ \\
\hline UpyMA & 2-ureido- $4[1 \mathrm{H}]$-pyrimidinone motifs \\
\hline UV & Ultraviolet \\
\hline YIGSR & $\begin{array}{l}\text { Tyrosine-isoleucine-glycine-serine- } \\
\text { arginine }\end{array}$ \\
\hline
\end{tabular}

\section{Background}

Additive manufacturing, commonly known as 3D printing is generating considerable interest owing to the vast applications in various fields, with the most important ones in pharmaceutical and medical research. This versatile technology has made tangible and innovative breakthroughs due to an increasing demand for customized devices in personalized therapy and diagnostics in addition to bio-inspired medical devices. The technique requires printing one or more materials in a layer-by-layer manner with a $3 \mathrm{D}$ printer, and by adjusting the shape of each individual layer, a complex, solid object can be formed from a digital model. The main advantages of 3D printing include high reproducibility and control, fast manufacturing, individualized product series, facile modifications of a product at a designed level with no restrictions on its spatial arrangement and convenient cost-effective manufacture [1]. The most significant applications are found in regenerative medicine (mainly tissue and organ fabrication), ophthalmological implants, 3D printed drugs, customized prosthetic, medical phantoms and cancer research.

There are various types of 3D printers, which are using different speeds and resolutions, but the main operating principles are based on either extrusion or powder/liquid solidification [2]. These techniques have specific strengths, disadvantages, and limitations. Regardless of the differences in material deposition mechanism, firstly a computer-aided design (CAD) file is prepared based on the desired model, then the 3D printer follows the instructions of the CAD file and builds the object in specific predefined patterns by moving the print head along the $\mathrm{x}, \mathrm{y}$ and $\mathrm{z}$ directions (Fig. 1) [3]. The materials used as ink formulation covers a wide range of compounds from plastics, metals, ceramics, or a combination thereof making the process highly versatile.

Since the field has made a substantial leap forward, there has been a rapid rise in the uses of biocompatible materials and even living cells into complex 3D functional products that have given rise to a plethora of advances in the medical domain due to their ability to mimic biological functions. This AM technology is also called 3D bioprinting. As in conventional 3D printing, it produces objects based in a layer-by-layer approach. Generally, two strategies are used: fabrication of acellular functional scaffolds which are further seeded with cells and cell-laden constructs developed to mimic their native analogues

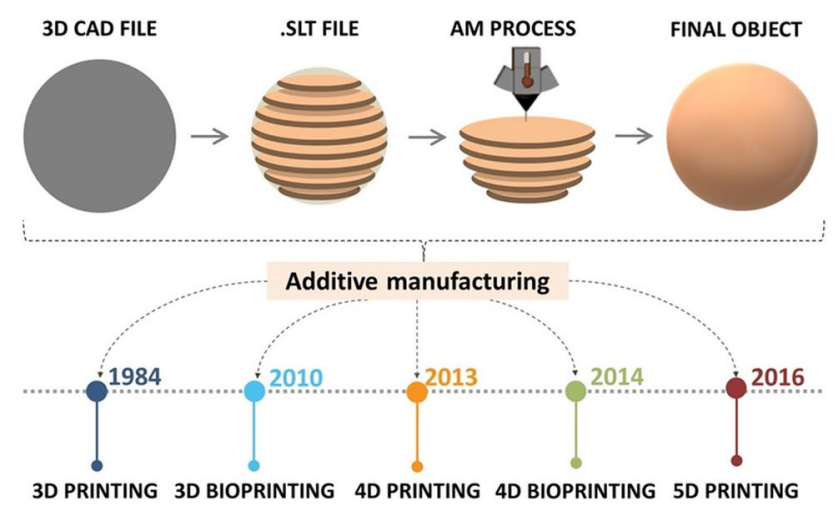

Fig. 1 Schematic illustration showing the AM process flow and evolution over the years 
[4]. An alternative approach can be in vivo bioprinting, the technique in which cells and materials are deposited directly into or on the patient. This can be a solution for in vivo regeneration of tissues right after an injury or to accelerate healing [5-7].

Specialized bioprinters use biological inks (often called bioinks) such as cytocompatible hydrogels. Hydrogels are defined as insoluble hydrophilic polymeric networks which have the ability to swell and absorb a high degree of water without disintegration. Hydrogels are particularly attractive materials for such applications due to (i) their ability to mimic the ECM, (ii) their tunable characteristics that allows an efficient and homogenous seeding of various cells and (iii) they possess a porous structure that allows the transfer of different nutrients, fundamental for cell viability and differentiation $[8,9]$. Hydrogels can also provide support for printing of high resolution, customized 3D geometries. Furthermore, self-healing hydrogels with shear-thinning properties allow the ability to print in any direction $[10,11]$. Even though 3D bioprinting has shown varying degrees of success, it has a major drawback as stated in Gao et al. paper [11]. The main downside is that $3 \mathrm{D}$ printing only takes into account the initial state of the printed structure and supposes is static and inanimate. To overcome this problem, a new concept called 4D printing was introduced in 2013, allowing bioengineered constructs to be pre-programmed to evolve in a particular way after printing [12]. Unlike previous technology, 4D printing uses the ability of shape and functionality transformation over time when exposed to an intrinsic/external stimuli allowing a more accurately imitation of the dynamics of the native tissues, and is based on the integration of smart biomaterials [13-16]. Among the possible responsive materials, self-healing polymers, thermally activated polymers, smart/nano-composites, piezoelectric materials, shape memory alloys and shape memory polymers have gained increasing interest [17]. Furthermore, as expected, $4 \mathrm{D}$ bioprinting or laser assisted bio-printing has recently emerged. 4D bioprinting is a specialized extension of 3D bioprinting that aims at reconstructing the biochemical and biophysical composition, as well as the hierarchical morphology of various tissues using stimuli-responsive biomaterials and cells [18].

Five-dimensional (5D) printing was introduced in 2016 by Mitsubishi Electric Research Laboratories (MERL) by William Yerazunis. Five-axis 3D printing is an extension of $3 \mathrm{D}$ printing where the print head has the ability to move around from 5 different angles due to a mobile plateau. This allows creating curved layers which are stronger than the traditional 3D printed flat layers [19]. Furthermore, this means that curved-shaped products or implants with improved strength can be produced with promising applications in orthopedics and dentistry [20].
The technological advances of AM are outlined in chronological order in Fig. 1. The image also depicts the typical work-flow of AM printing process.

In this article we provide an overview of the newest development and achievements in the field of additive manufacturing and explore the potential for growth and current limitations of this technology. The parallel development of $3 \mathrm{D}$ and $4 \mathrm{D}$ printing is summarized and compared with a special effort made to point out their applications in the biomedical field. The influence of Machine Learning (ML) in the field of AM is examined with an emphasis on the benefits induced by this new technology. Lastly, current challenges and outlook are discussed. This paper aims to cover more recent studies compared to other review papers on additive manufacturing based on polymers as they are by far the most utilized class of materials for AM [1, 21-26].

Polymers are the most common assemblies used in 3D printing technologies, providing a multitude of compositions and the ability to modify their structure and surface, requirements solicited by specific applications, including the addition of additives to improve the basic properties of plastic materials, as for example, antimicrobial compounds [27-31]. Surface chemistry, mechanical properties, and topography of functional polymers prove to be three major parameters for their effective use in AM technology. They also meet the requirements for products that apply to $3 \mathrm{D}$ printing, such as the existence of specific melt flow index/melt flow rate; crystalline behaviour in interdependence with the polymer chains nature and composition; specific thermal properties in correlation with the glass transition temperature and melting temperature; thermal conductivity properties improvement with addition of fillers.

\section{From 3d to 4d Printing}

The printing technology is conceptually derived from the process of additive manufacturing that primarily aims at designing and manufacturing functional constructs based on the controlled layering of various materials that merge into a final product with desired characteristics and dimensions, encompassing three-dimensional geometries. Due to the growing need for customization, the world demand for $3 \mathrm{D}$ printers, materials and software is expected to grow from year to year by $-20 \%$, the fastest progress being anticipated in the medical market [1].

Various methods have been developed and evolved with the technological progress and can be classified according to the procedure applied to assemble the material or its physical state [27]. The most commonly used approaches for processing pure polymers and polymer nanocomposites for the biomedical field includes stereolithography, inkjet, microextrusion, and laser-assisted printing [32]. 
Stereolithography, the first patented and the most accurate of the techniques (a precision of up to $20 \mu \mathrm{m}$ can be obtained compared to other techniques that allow an accuracy of up to $50 \mu \mathrm{m}-200 \mu \mathrm{m}$ ) is based on photopolymerization of vinyl monomers [27]. The curing is activated by the decomposition of a photoinitiator into free radicals when exposed to ultraviolet (UV) or visible light sources. Even though this technique is extensively used to produce polymeric scaffolds, the simultaneous printing of cells is not recommended due to the fact that photoinitiators are usually insoluble in water and need to be dissolved in organic solvents. This can be highly toxic for cells and a major drawback for stereolithography. Another issue is that UV light can damage the cell during curing, so they are usually embedded in the scaffold after printing [27].

Inkjet $3 \mathrm{D}$ printing is characterized by a short fabrication time and low costs. It uses thermal, piezoelectric, or electromagnetic tools to deposit small ink droplets (called binders) through a nozzle in a layer of powder. When printing polymeric scaffolds, the binder is a solvent in which the polymer is dissolved. Once the solvent evaporates, the macromolecular compound reprecipitates and forms the desired solid structure [33]. However, these method applications have been limited when compared to other techniques, due to the clogging of the nozzle, inability to ensure a continuous flow of the ink and also a reduced functionality for vertical structures [9].

Extrusion is a simple but limited technique because is capable of printing biomaterials only in the form of viscous liquids (in the range between $30 \mathrm{mPa} / \mathrm{s}$ to $>6 \times 10^{7}$ $\mathrm{mPa} / \mathrm{s}$ ) and a low resolution is obtained [9]. There are several extrusion-based printing methods, such as pneumatic (where air pressure is used), and piston or screw-driven dispensing (when vertical and rotational mechanical forces allows printing). For medical applications, microextrusion is often employed, since it can deposit cells at a higher density [34].

Laser-assisted bioprinting is a nozzle-free technique that allows a high-resolution deposition of either solid or liquid materials. The process of printing is based on the transfer of energy from a laser beam to a ribbon, which then deposits the polymer onto a substrate. As a disadvantage, one can mention the high cost and also the thermal damage that occurs due to nanosecond/femtosecond laser irritation.

Since 4D printing is a very new concept, there are few technologies suitability for printing adaptable objects [35]. Poly-Jet (Stratasys Ltd) is used to produce multi-material objects and is based on depositing curable liquid photopolymers in a layer-by-layer manner. Selective laser melting (SLM Solutions) is used for producing metallic components. Recently, to enable 4D printing for biomedical applications, a technology suitable for printing polymeric solutions called direct-write printing (DW) has been developed [36, 37].
Furthermore, there is no question that new concepts of 4D printers should be developed or that existing 3D technologies should be improved in the foreseeable future. This should be pursued in parallel with the improvement of the materials [38].

\section{Key Properties Required for AM Technology}

Polymeric materials have been widely utilized as inks due to their versatility, low weight, low cost, processing flexibility and mechanical and physicochemical properties. The correct choice of material is a critical step in the printing process and can lead to constructs with improved functionality, good mechanical properties and customized 3D geometries. The materials range from thermoplastics, thermosets, polymer-based composites to polymers blended with various biomolecules [12]. The generation of complex, functional archetypes and life-changing products for biomedical applications has induced the need for printing with biocompatible or 'biofunctionalizable' inks, also called bioinks. Their composition and design is based upon the type of printing employed and targeted application, but typically they are composed of the matrix components (usually cyto- and biocompatible hydrogel precursor formulations or block copolymers), nutrients, and/or bioactive signals [39]. Some polymeric mixtures include living cells isolated from the patient and raised in the laboratory. During the printing the bio-ink fluid is gelled by physical, chemical or photocrosslinking procedure in order to preserve its shape and to minimize the structure collapse. A required condition is that the gelation should occur after the material exits the nozzle tip to prevent blockages inside the printing head. The final bioink construct consists of a template that acts as a support for the suspended cells [40].

In order to satisfy various end bioapplications, 3D inks are mainly formulated for having the following properties: printability, structure, toughness, elasticity, recyclability and biocompatibility. Techniques based on extrusion usually demand higher viscosity and shear-thinning properties. On the contrary, techniques based on inkjet need lower viscosity inks with a reduced sol-gel response and transition time [41].

The 3D fabricated construct must have a proper resemblance to the natural tissue in terms of shape and structure and they should not cause a negative immune response or toxicity. Hydrogels should (*) have good mechanical properties in order to support the deposition of the upper layers, (**) maintain their proper shape during and after the printing process, $(* * *)$ should encourage cell proliferation and differentiation. At the same time, gels with high concentration of polymers can keep optimal shape fidelity, but they can also limit cell proliferation and subsequent differentiation due to the formation of a denser network. Conversely, softer 
gels are more appropriate for cell-based applications, but they cannot maintain a proper shape, so a suitable strategy should be chosen to improve the design of these materials. Consideration should be given as well to the environment in which the material will be exposed (e.g. temperature, $\mathrm{pH}$, humidity, chemical exposure, radiation, UV light) and if the selected material requires being biodegradable $[4,42]$. The chemistry and topography of the 3D structures surfaces are also crucial factors that influence the interaction with the biological environment [43]. If a high-level of printability is desired, an improvement of the mechanical properties of the 3D scaffolds can be acquired by using composite-hydrogels.

In the case of $4 \mathrm{D}$ printing, additional properties are required and polymers or polymer composites are almost exclusively used in this technology since they are more diverse in terms of both active shape-changing behaviours and material designability [12]. Either single materials or a combination of materials can be used. When using the latter, particular attention must be paid to the mathematical modelling applied in the first phase of the printing process, which allows a precise distribution of the components in the final structure.

The inks must meet clear requirements in terms of achieving self-assembly, self-repair, shape-shifting, predictability, responsiveness, and multi-functionality. Shape-shifting refers to both shape-changing materials (a structure that changes shape immediately after a stimulus is applied and then returns to its original form after the stimulus is removed) and shape memory materials (defined as a material returning to a predefined shape when a stimulus is applied) [44]. The shape change behaviours include folding, bending, twisting, linear/ nonlinear expansion/ contraction, curling the surface and generating surface topography characteristics [45]. In some cases, smart materials do not necessarily need to have the ability to change shape. Equally important is the ability to change colour, hardness or transparency. These properties are of great significance in camouflage technology or for medical sensors [46].

Due to their ability to swell when they come in contact with a suitable solvent, hydrogels can be used in $4 \mathrm{D}$ printing. However, some disadvantages should be mentioned: they have an inherent weakness, can suffer mass losses during the hydration/dehydration cycle and the actuated shape may not be stable due to the volatility of water. These features can threaten the integrity of the printed construct. To address this issue, innovative designs such as double networks, bi-layered structures or hydrogel composites have been developed [46].

As for 4D bioprinting, since this technology has just emerged, there are several important challenges that need to be addressed first, such as (i) the $4 \mathrm{D}$ constructs requires synergy between cells and the bioink; (ii) the cells must survive both the printing process and the stimuli required to shape change; and (iii) the response capability of the 4D fabricated construct must not be diminished by the inclusion of cells [47]. A general comparison of the aforementioned printing technologies is shown in Fig. 2.
Fig. 2 Schematic illustration showing the main differences between 3D (bio)printing and 4D (bio)printing

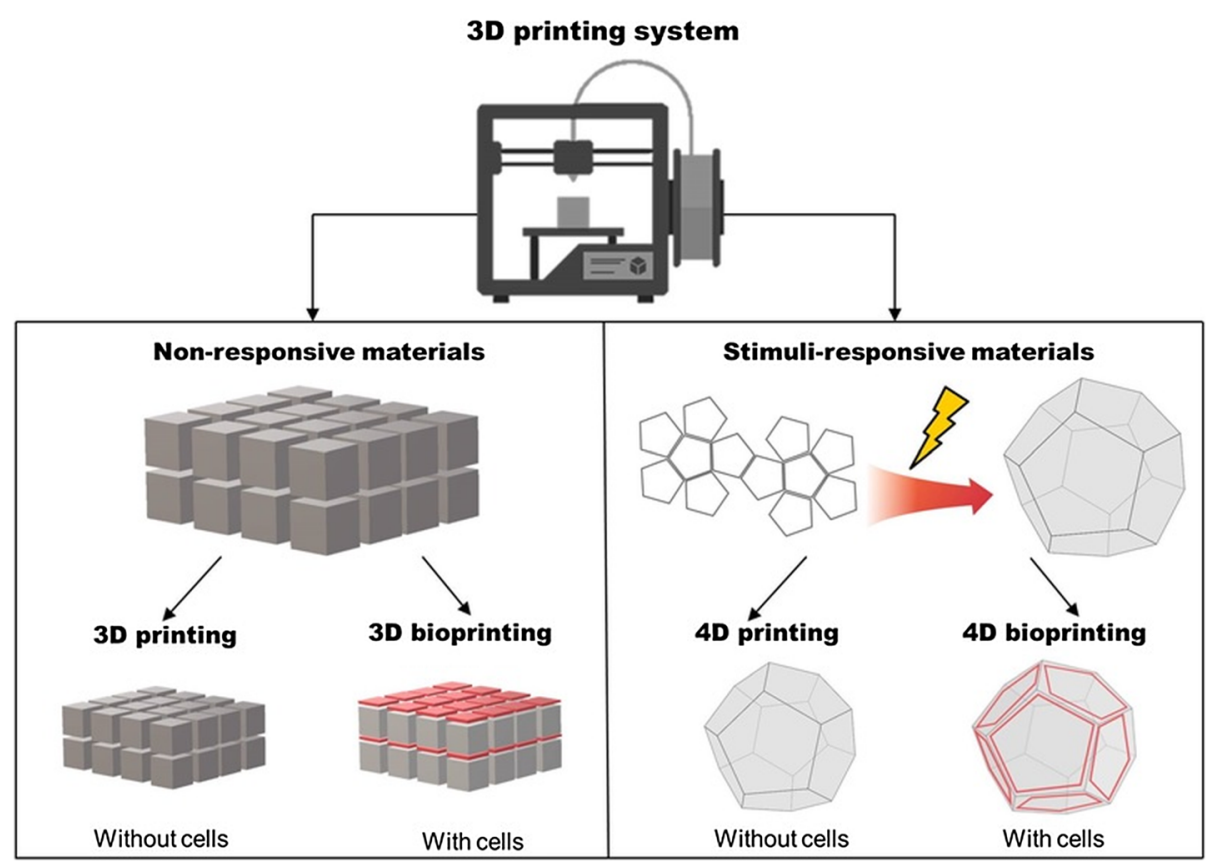




\section{Polymers and Polymer Composites Prepared for 3D (bio)Printing}

Both natural and synthetic polymers are predominantly used as inks, each with corresponding advantages and limitations and all playing a pivotal role in this quest. An increasing number of studies have been published lately on natural polymers due to their chemical and structural similarity to the native tissue microenvironment, selfassembling ability, biocompatibility and biodegradation properties, all leading to a better cellular response [48]. The most explored are alginate, HA, collagen and chitosan. However, synthetic polymers can be easily modified to meet specific requirements by optimizing mechanical and physicochemical properties, $\mathrm{pH}$ and temperature responses or they can be functionalized with various biomolecules. Some of the synthetic polymers that are frequently used in printing include PC, PLA, PGA, PEG. [49] Other strategies involve blending of natural polymers with synthetic ones, or using polymer-nanocomposite bioinks in an attempt to enhance and adapt the cellular responses within the $3 \mathrm{D}$ constructs. A fundamental issue for future research is the optimization of polymer-polymer interactions along with polymer-cell interactions while preserving printability [49].

Alginate is one of the most commonly used natural polymers for 3D printing due to its excellent biocompatibility and the ability to easily obtain hydrogels in physiologic conditions $[34,50]$. In order to avoid poor printability that occurs in direct bioprinting process, Naghieh et al. [51] have created an alginate hydrogel for nerve tissue engineering applications by using indirect bioprinting. This method involves the application of a sacrificial framework that temporarily supports the formation of the polymer scaffold. Gels with various polymer concentrations were obtained $(0.5 \%$, $1.5 \%$, and $3 \%$ ) wherein the sacrificial framework was based on a $50 \%$ gelatine scaffold. The results show that both the mechanical and biological properties of the fabricated scaffolds are affected by the concentration of alginate as well as the proposed sterilization technique (ethanol disinfection or UV irradiation). The scaffolds were characterized biologically using Schwann cells and showed a better cell functionality when fabricated with a lower concentration of alginate compared to a higher one. The strategy of manufacturing and testing the printed material is briefly illustrated in Fig. 3 .

In a similar work, Sarker et al. [52] has developed a bioprinted peptide-conjugated sodium alginate scaffold for peripheral nerve tissue regeneration. The study investigated
Fig. 3 3D bioplotting of alginate hydrogels: a cultivated Schwann cells mixed with alginate hydrogel and then bioplotted, b cell-incorporated alginate scaffold and staining result showing one strand, and c poor printability of $0.5 \%$ alginate printed with a $100-\mu \mathrm{m}$ needle and staining result of cell-incorporated gel [50]

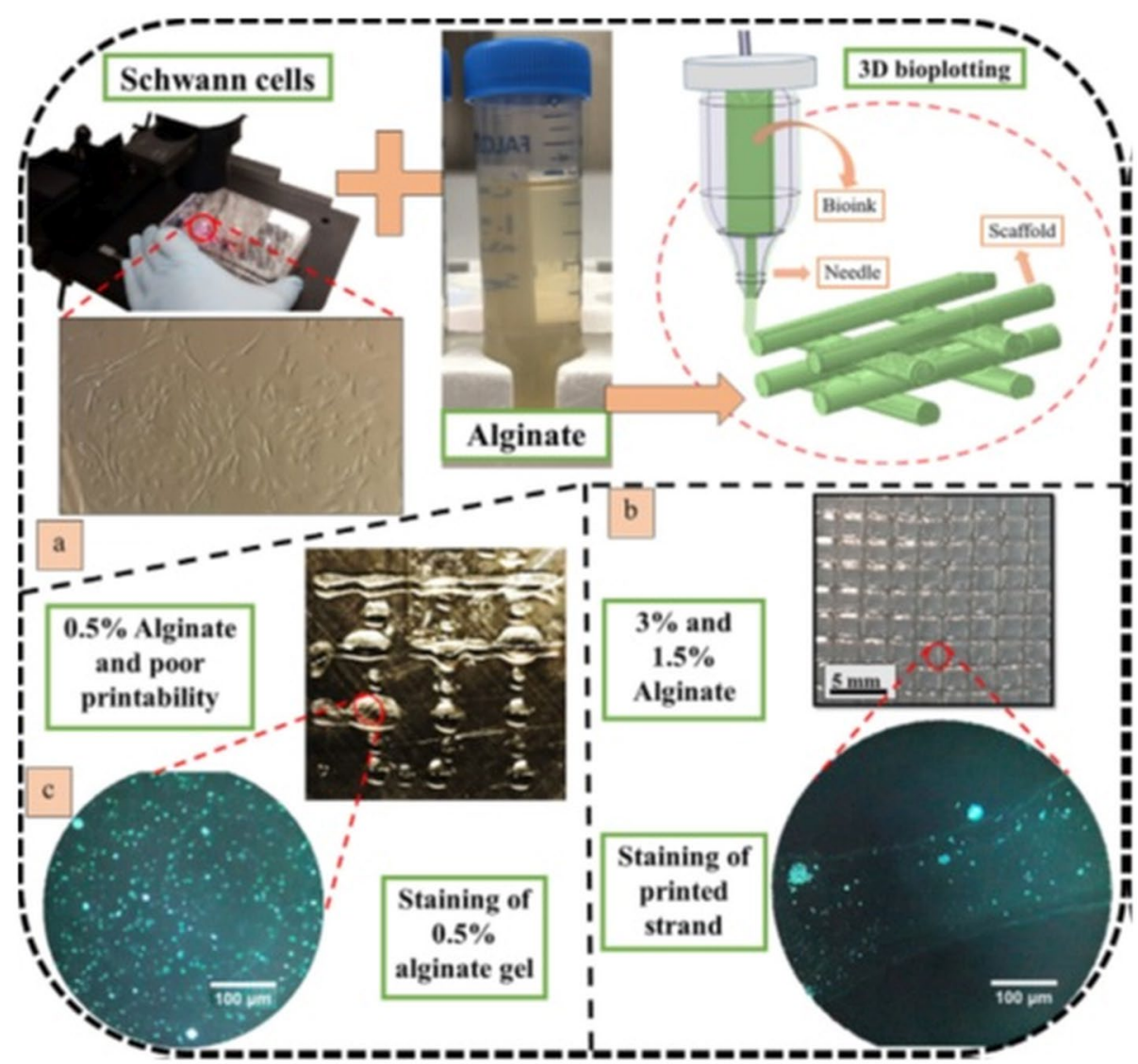


whether the proposed biomaterial can be supportive for axon outgrowth. Their approach was based on the conjugation of a $2 \%$ alginate precursor with either RGD or YIGSR peptides, and/or a mixture of RGD and YIGSR. The biological properties were evaluated by estimating the viability of Schwann cells, the amount of secreted brain derived neurotropic factor, and directional neurite outgrowth of neuron cells. Mechanical stability was measured by incubating the scaffolds in physiologic buffer over 3 weeks. The materials preserved their initial porous structure after this time, but lost $-70 \%$ of the elastic modulus.

A porous structure is essential for adsorption of proteins, cell migration, proliferation and vascularization of newly formed tissues in scaffolds [53]. In this regard, Wei et al. [54] has successfully designed an alginate hydrogel with controlled macropores and micropores by using 3D printing and leaching of recrystallized salts. Their strategy was recommended for tissue engineering applications. Instead in the Lewicki et al. [53] study was reported a freeform reversible embedding of suspended hydrogels 3D bioprinting method for creating constructs populated with human neuroblastoma cells SK-N-BE (2) using the alginate-based hydrogel material.

Furthermore, various inks based on alginate blends with methylcellulose [55], nanocellulose [56], PVA [57], gelatin methacryloyl and 4-arm poly(ethylene glycol-tetraacrylate) [58], chitosan [59], honey [60], or gelatine [61, 62] have been proposed with promising applications in tissue engineering.

HA is a natural polysaccharide found in cartilages and connective tissues and widely used in medical applications due to its biodegradability, biocompatibility, nontoxicity, nonadhesivity, shear thinning properties, high water absorption capacity and non-immunogenicity $[63,64]$. It also has an important role in regulating cellular behaviours such as cell migration, angiogenesis, viability, and proliferation [65].

However, due to high water solubility, and low mechanical properties different strategies for improving post-printing stability have been reported in the literature. Primarily, blends of HA bioinks with natural or synthetic macromolecular compounds have been employed. Noh et al. [66] reported a $3 \mathrm{D}$ printed construct based on hyaluronic acid, hydroxyethyl acrylate, and methacryloyl-gelatine. The multi-component hydrogel was obtained by graft polymerization of hydroxylethyl acrylate to hyaluronic acid and then grafting of methacryloyl-gelatin via radical polymerization mechanism. The resulted bioink has excellent biocompatibility, good swelling, appropriate viscosity, shear-thinning, and viscoelasticity, cytocompatibility, has as well the ability to deliver small molecular drugs (such as dimethyl-oxaloylglycine) and most importantly the gel showed printability in good shape. In another study, HA was combined with methylcellulose to obtain bioprinted structures with high cell viability for tissue engineering applications [67]. The results showed that the mechanical properties can be easily regulated by altering the ratio between the polymers, and mesenchymal stem cells (hMSCs), encapsulated in the gel, survived the $3 \mathrm{D}$ bioprinting process and remain viable for one week. Furthermore, remarkable efforts have been made to regulate neuronal growth by using $3 \mathrm{D}$ polymeric networks based on HA [68].

Collagen, a major structural protein, has been widely used in the field of 3D printing, as it can induce biological properties and functions close to those of natural systems to the printed scaffolds $[69,70]$. The most noteworthy collagenbased bioinks were designed for the repair of hard tissues [71, 72] and cartilage tissue [73-75]. Recently, Sun et al. [76] developed an innovative scaffold based on collagen and chitosan which demonstrated significant therapeutic effect on rat complete-transected spinal cord. This can be a breakthrough strategy for spinal cord nerve functional reconstruction. In the mentioned study, chitosan has been used to improve the mechanical strength of the collagen scaffold.

Chitosan is a cationic polysaccharide, well known for its biocompatibility, bioresorbability, biodegradability, antimicrobial activity, mucoadhesivity, and non-toxicity $[77,78]$. This natural polymer is commonly used as bioink because it exhibits a shear-thinning behaviour which is beneficial for extrusion-based 3D printing [79, 80]. Thus, Yang et al. [80] designed a scaffold based on chitosan-grafted poly(lactide-co-glycolide) and hydroxyapatite which has the ability to inhibit the bacterial biofilm formation and to restore infected bone defects. Studies conducted on two different infected bone defect models have shown that the scaffold has a dual antibacterial and osteogenic functionality and can be used to repair infected cortical and cancellous bone defects. Furthermore, hardystonite [81], silk particles [82], hydroxyapatite [83] and calcium phosphate [84] were incorporated into chitosan inks for mechanical reinforcement or to promote osteogenic differentiation in vivo, to be further used as bone substitutes.

Although natural polymers have proved to be suitable for application in 3D printing, adequate mechanical properties and versatility regarding the control of the physicochemical properties are still required. In this perspective, synthetic polymers or blends of natural and synthetic macromolecular compounds are a promising area to explore [4].

PCL has been widely utilized in 3D printing due to its high processability. Furthermore, owing to its excellent mechanical strength, PCL has been successfully used to create bioresorbable cardiovascular stents in a one-step process by using Fused Filament Fabrication and a 3 -axis 3D printing technology. The stents showed a good radial behaviour with an average of $320 \%$ of radial expansion and an average of $22.78 \%$ of recoil. The final characteristics of the printed device and the dimensional precision of the printing process 
were strongly influenced by the printing temperature and printing flow rate [85]. In addition, the authors continued the study and analysed the effects of various sterilization processes on the stability of PCL stents which showed that ethanol can be an effective sterilization treatment because it doesn't affects the material properties. Researchers have also approached acid poly(lactide), PLC and PCL/PLA blends for 3D printed stents to restore the functions of vascular tissue (Fig. 4). The PLA, PLC and PCL / PLA composite stents were additionally seeded with 3T3 cell and evaluated and compared with regards to cell proliferation, degradation rates, mechanical dilatation and radial dynamic tests to determine the best parameters for the medical device. The PCL / PLA blend stent, which showed medium levels of degradation rates and mechanical modulus, and a printing accuracy of $85-95 \%$, was proved having the best results [86]. Overall, these studies have shown that 3D printing technology may be suitable for the production of biodegradable cardiovascular stents which degrade in time to restore vessel patency and permit remodelling while maintaining recoil [87-89].

However, a disadvantage worth mentioning is the hydrophobic character of PCL, and high melting point $\left(60^{\circ} \mathrm{C}\right)$ which limits its use as cell-laden bioink $[90,91]$. To overcome this issue, blends and block copolymers of PCL with various macromolecular compounds and biomolecules such as alginate, PEG, PVAc have been used to produce inks with tuned characteristics for biomedical applications [92-96].

PLA is a biocompatible polymer that has been approved by the FDA for biomedical applications such as tissue engineering, controlled drug delivery systems, and orthopaedic implants [97, 98]. This polymer is used intensively in 3D bioprinting because it is less viscous allowing adequate flow through an inkjet nozzle, which facilitates processability through extrusion, injection moulding or casting [91, 99]. Many recent studies focus on the mechanical and biocompatibility/bioactivity properties of PLA or its blends after 3D printing [100-103].

A direct strategy of influencing and enhancing cellular response is by modifying the surface chemistry of the 3D geometries based on PLA. In this context, an interesting study is that proposed by Kao et al. [104] who selected PLA for the fabrication of 3D scaffolds coated with PDA to be used in bone tissue engineering. PDA is a simple and versatile surface functionalization method, inspired by the adhesive nature of catechols and amines in mussel adhesive proteins $[105,106]$. In the mentioned article, researchers concluded about the improvement of the bio-inspired surface modification of the human adipose-derived stem cells (hADSCs) adhesion and proliferation when compared to the unmodified PLA scaffolds.

In a similar study, 3D printed scaffolds of PLA with 70\% porosity were prepared by materials extrusion and modified to augment bone repair and tissue regeneration [107]. In order to improve bioactivity, a strategy of surface grafting with functional moieties has been proposed. PEI which has the ability to facilitate cell proliferation and osteogenesis, was conjugated to the surface of the $3 \mathrm{D}$ construct and it was further used for grafting ca., a bone component that has the role of precipitating the apatite phase during the bone formation. Apatite minerals were deposited by immersing the material in SBF. The proposed materials showed promising properties like improved wettability, increased cell adhesion and cell proliferation of hMSCs, sustained release of calcium ions in aqueous medium and enhancement of osteogenic differentiation on the surface modified PLA scaffolds when compared to neat PLA.

Several researchers have reported other post-printing strategies to improve surface properties and demonstrated their advantages for regenerative medicine applications such as cold atmospheric plasma [108], chemical hydrolysis, UV/ Ozone irradiation, gold thin film deposition [109], and surface modification with peptides. An excellent review that investigates extensively this research topic is the one proposed by Baran et al. [110].

Another polymer similar to PLA is PGA [111]. Particularly, PGA and PLA copolymer, namely PLGA has been exploited in a variety of studies and has demonstrated tremendous potential in AM technology $[112,113]$ An interesting work is that proposed by Chen et al. [114], where C2C12 myoblast cells seeded on a PLGA scaffold fabricated by E-jet 3D printing were studied and it was found out that
Fig. 4 Stent configurations: a Stent cell geometries employed; b Stent material/layers used [88]

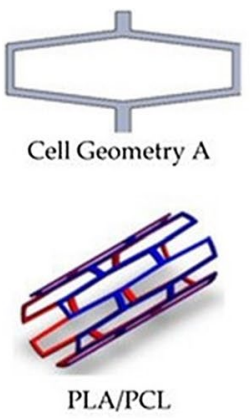

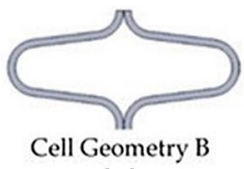

(a)

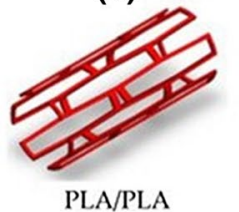

(b)
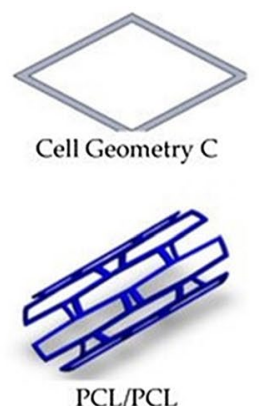

PCL/PCL

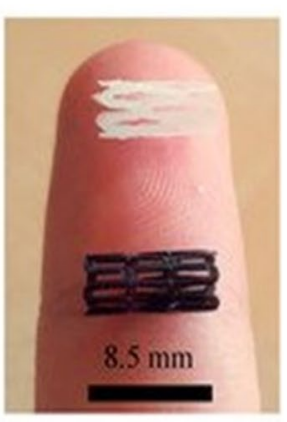


the polymer platform is biocompatible, can enhance cell adhesion and proliferation thus proving the use in skeletal tissue engineering and regeneration.

PEG a biocompatible and hydrophilic polymer, has also found application in this domain. Recently, PEG microgels prepared via electro-spraying and off-stoichiometry thiolene click chemistry, and use as bioink for the development of complex tissue structures, has been reported [115]. The strategy proposed in this study was based on the fact that microgels can be easily extruded through a nozzle head and can also form stable constructs due to the inherent cohesive forces between the polymeric microstructures. Furthermore, silk fibroin-PEG composites fabricated by digital light processing 3D printing were successfully used to print an artificial skin model [116].

Although pure polymers can be successfully used as inks for AM, as the technology advances, the development of new, complex materials is required. One of the strategies to create mechanically advanced polymer scaffolds with enhanced regenerative potential and printability is by incorporating reinforcing materials such as metals, ceramics, or nanostructures into the ink. The development of hybrid materials that are compatible with the available printing technology has been the focus of many studies in the past six years, and some examples have already been mentioned above $[117,118]$.

Therefore, inks containing fibers to adequately control the mechanical behaviour of the 3D fabricated construct are being explored. The most commonly used materials for the production of both short or continuous fibers for AM technology are glass and carbon [119]. The main challenge is given by the density, distribution and the ability to orient the fibers inside the matrix during the printing process. All these factors determine the stiffness and strength of the final composite [120-122].

In addition, fillers based on particles, either in powder or liquid form can be blended directly into the polymer matrix and can improve mechanical properties, bioactivity, biocompatibility or degradability [118]. However, when particles are added, particular attention should be paid to the sedimentation and homogeneity of the filler.

By dispersing inorganic nanomaterials into polymers such as metal or ceramic nanoparticles (1-100 nm), carbon nanofibers, carbon nanotubes, nanowires, quantum dots or graphene, high-performance composites can be designed [123]. This is mainly due to the high surface area-to-volume ratio surface interaction between the nanofiller and macromolecular compound, as well as to the new functions added to the host matrix [124]. For instance, by adding magnetic $\mathrm{Fe}_{3} \mathrm{O}_{4}$ nanoparticles to a mesoporous bioactive glass/PCL composite scaffold, a new 3D printed material capable of enhanced osteogenic activity, local anticancer drug delivery and magnetic hyperthermia has been obtained [125].
Furthermore, $\mathrm{TiO}_{2}$ nanoparticles enhanced the compressive modulus of PLGA porous scaffolds as well as its biological performance [126].

The most remarkable, recently developed polymeric composites used in 3D printing and the properties improvements of the resulting materials are presented in Table 1.

The morphology and geometry of the 3D structures strongly rely on their final application; in this regard, a wide variety of 3D patterns can be developed based on polymers and composite materials, as it can be seen in Fig. 5 .

\section{Smart Materials and Stimuli-Responsive Mechanisms for 4D Printing}

In order to mimic structures inspired by nature, 4D printing promotes dynamic and structural reconfiguration over time, thus surpassing the static nature of $3 \mathrm{D}$ printing. This is achieved through the use of complex structures (comprising one or combinations of materials) with stimuli-responsive mechanisms [151]. There are several types of stimuli and they can be categorized into physical (such as temperature, liquid/moisture, light, magnetic field, electric field), chemical (pH and ionic concentration) or biological (glucose, enzymes) [152].

Temperature is the most reported stimulus and has already been implemented in other medical application such as drug delivery [153]. The materials usually display a volume change or a deformation (such as folding, curling, expansion or various other programmed shapes) at a specific temperature. Invernizzi et al. [10] have reported a self-repairing $4 \mathrm{D}$ multifunctional material that can be used in the production of components for human-machine interactions and soft robotics. The material is based on photo-crosslinking PCLDMA macro-monomers with methacrylates bearing UPyMA motifs. To analyse the thermally activated shape memory effect and self-healing properties of the proposed chemical structure an opposing thumb with a forefinger was printed via DLP technology. The sample was further partially cut. Next, the material was heated to a temperature higher than the PCL melting temperature (Tm), which allowed the sample to be deformed in a desired temporary form. Once deformed, the structure was cooled down in order to fix the temporary shape by the crystallization of PCL crystalline domains. Re-heating the structure at a temperature $\mathrm{T}>\mathrm{Tm}$ allows the sample to recover its initial printed shape, thus demonstrating the potential to be used as actuator devices in soft robotics applications. Furthermore, various complex and intricate folding transitions have been obtained by using the conventional properties of shape memory thermoplastics polymers (SMP) such as PLA, ABS, $\mathrm{PC}$, and PU $[154,155]$. 


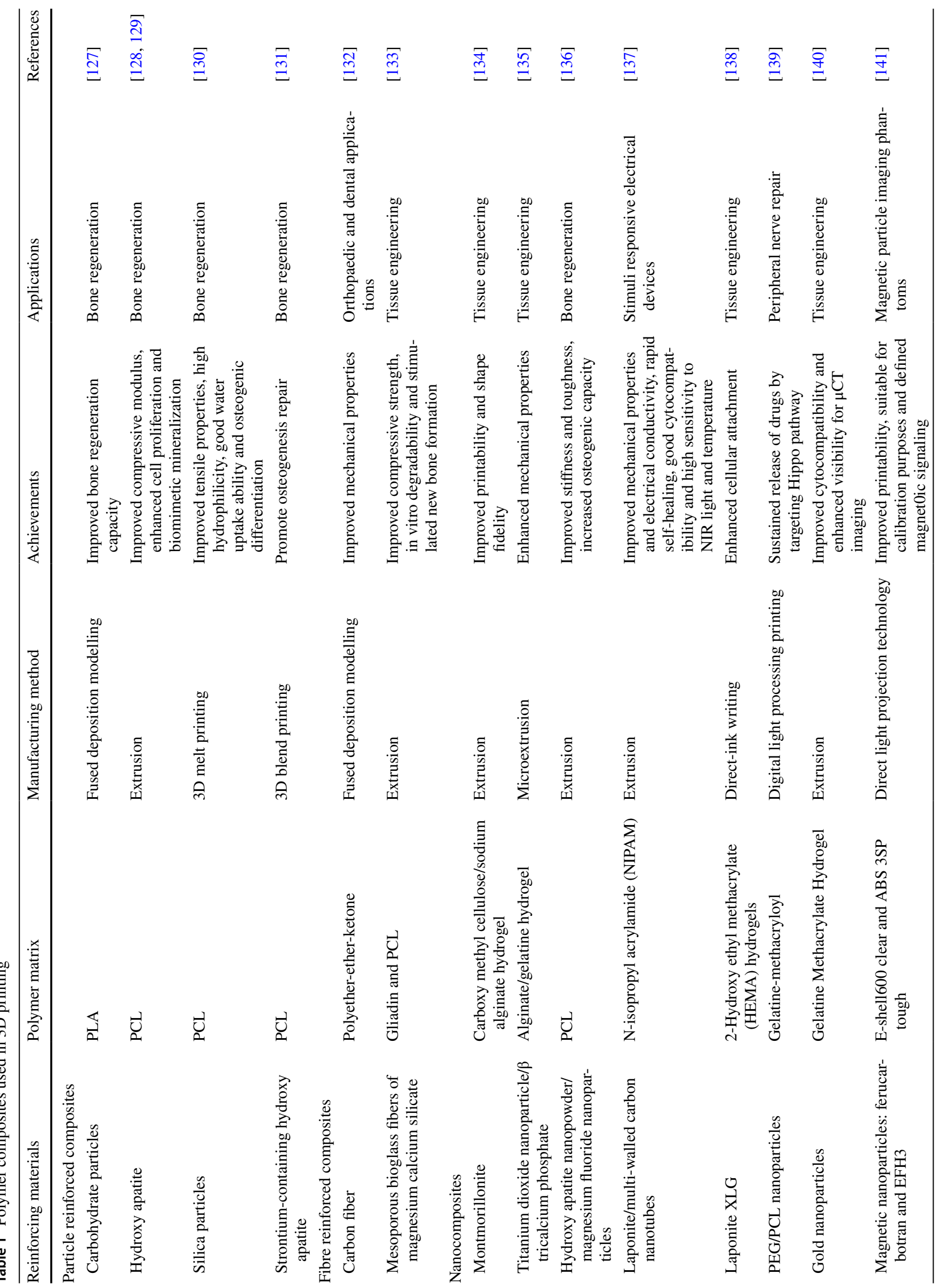


Hydrogels can also exhibit temperature-sensitive properties that can be employed to produce smart 3D objects. Most studies focus on the use of pNIPAM as a building block because it exhibits a large and reversible volume change in water at a temperature called LCST, typically $32-35{ }^{\circ} \mathrm{C}$ [156, 157]. For instance, Bakarich et al. [158] proposed an alginate/pNIPAM gel that is both mechanically robust and thermally actuating. The materials exhibited reversible length changes of 41-49\% when heated and cooled between 20 and $60{ }^{\circ} \mathrm{C}$. In addition, the authors were able to successfully print smart valve that automatically close upon exposure to hot water, reducing the flow rate by $99 \%$.

Recently, bioinspired tubes composed of an active thermally responsive swelling gel pNIPAM and a passive thermally non-responsive gel (p.a.) have been reported [159]. The high-swelling and low-swelling gels were symmetrically arranged in tubular geometries to achieve uniaxial elongation, radial expansion, bending, and gripping. Figure 6 illustrates the printed object which was inspired by a coral polyp, capable of simultaneous elongation and gripping; the tube can reach into a tank and grab an object. This approach can be further extended to the 4D printing of more complicated assemblies to facilitate their use in soft-robotics.

Another stimulus of high interest is water/moisture, where deformation is based on different levels of water sorption (i.e., swelling) [160]. Typically, the strategy followed is based on the fact that the swelling of the various compartments within the material occurs in a spatially and temporally dependent manner. A water sensitive 4D structure was recently proposed by Mulakkal et al. [161]. They have successfully developed a stimuli responsive hydrogel composite ink based on sodium CMC, cotton derived pulp linters (as the cellulosic fibre component) and montmorillonite. Another humidity responsive platform can be achieved by using PEG diacrylate hydrogels fabricated by photopolymerization [162]. Literature also mentions studies that implement both hydration and temperature sensitivity in their materials [163].

Recent developments in smart materials enable the reconfiguration of 4D printed structures into different shapes when exposed to different light stimuli [164]. Using light as a stimulus has the advantage that the material can be changed both remotely and non-invasively. For instance, a composite that integrates a thermo-responsive polymer gel and photosensitive fibers exhibit a distinct response to the different applied stimuli [164]. Namely, the material bends in one specific direction under the influence of heat and bend in the opposite direction in the presence of light, showing that the material can be highly reconfigurable.

Another controllable, non-invasive stimulus that provides a quick response and has the potential to increase the level of control is magnetic field. Researchers discovered and developed a composite ink system based on PDMS and iron 
Fig. 5 3D printed objects fabricated using different AM techniques: a PCL/PEG polyblend scaffold for bone regeneration; [94] b PCL, PVAc and hydroxyapatite composite porous scaffolds employing bone regeneration; [96] c 3D printed nose based on a alginate-chitosan complex hydrogel; [59] d native anatomic and axisymmetric aortic valve geometries printed with PEG-diacrylate hydrogels; [145] e various 3D anatomical geometries based on PEG-alginate-nanoclay hydrogels; [146] f PEG hydrogel microspheres as bilding blocks for 3D printed scaffolds; [115] g vascular structures based on alginate; [147] h 3D-printed artificial trachea scaffolds based on PCL; [148] i 3D printed anterior cruciate ligament screw from PLAmagnesium- $\alpha$-tocopherol; [149] j 3D scanned models of wrist splints based on PLA; [150]. Reproduced with permission
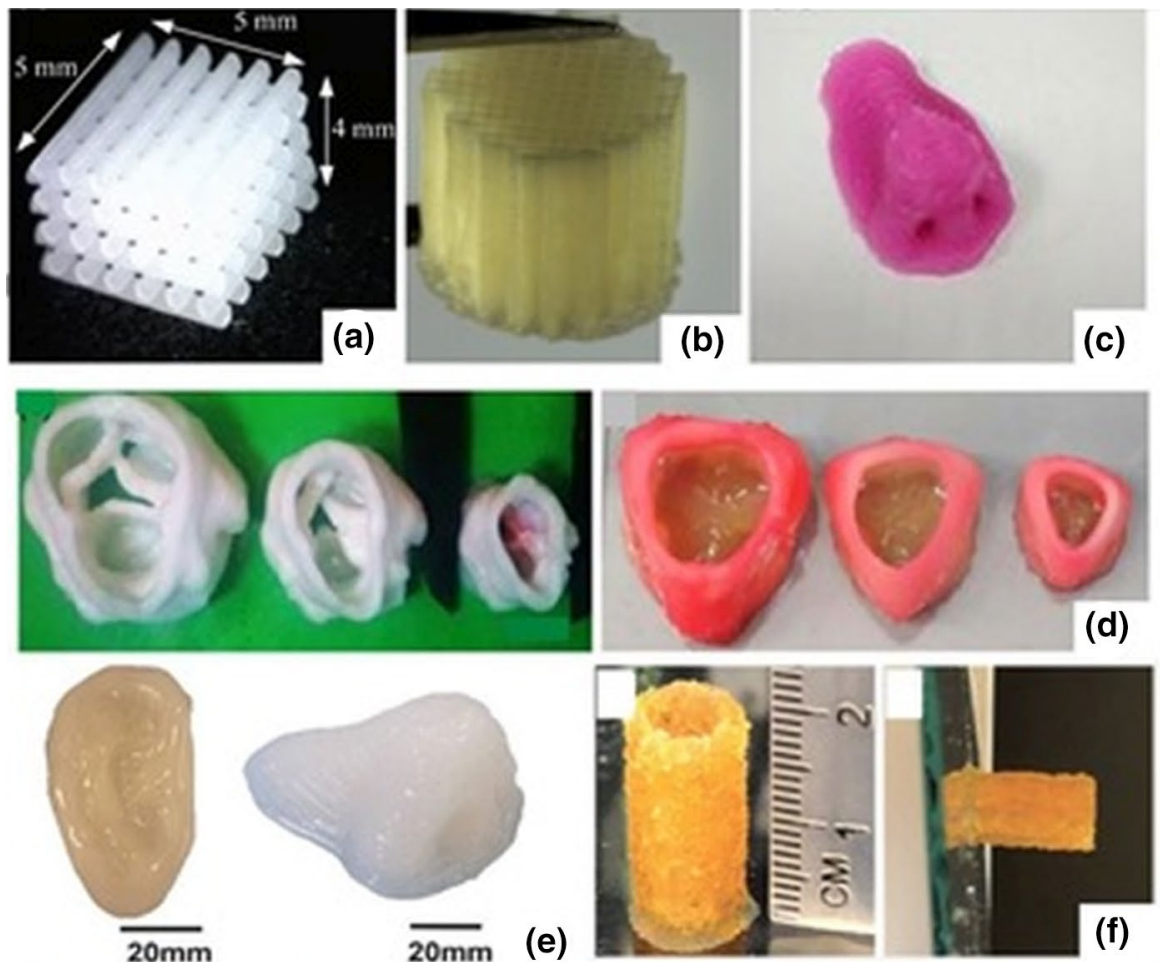

$\overline{20 \mathrm{~mm}}$

(e)
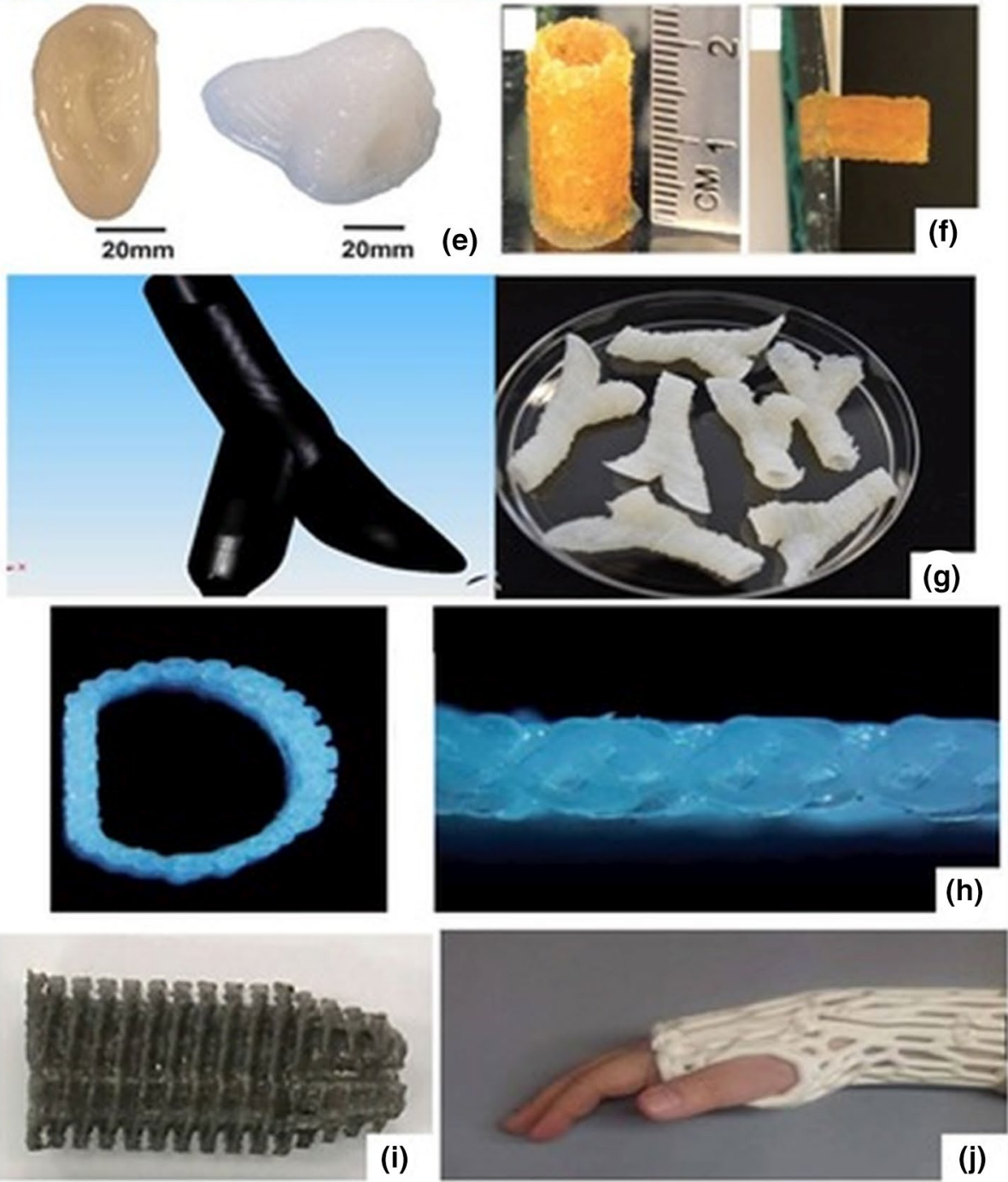

nanoparticles which has the potential to be used for various magneto-mechanical applications [165]. PDMS serves as the flexible matrix component while the magnetic particle subjected to the magnetic field could obtain or lose their magnetization due to their low magnetic coercive force and high permittivity, compelling macroscopic change. Furthermore, the printed material changes its shape under the magnetic force but recover its initial configuration due to the 


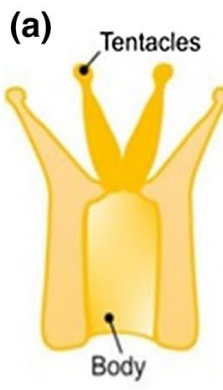

Coral Polyp (b)

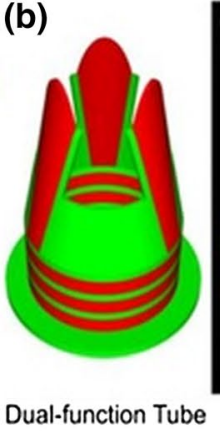

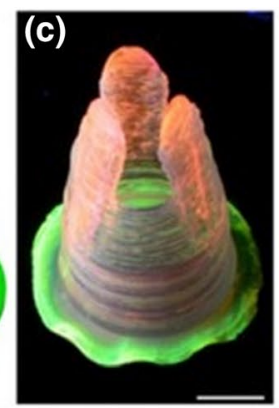

Photocured

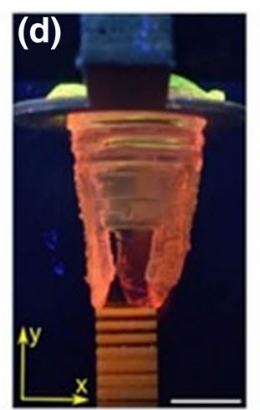

$25^{\circ} \mathrm{C}$ in Air

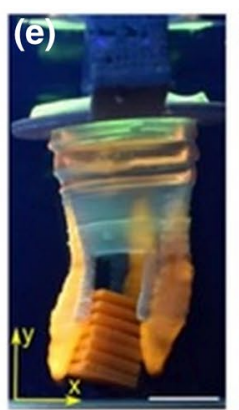

$25^{\circ} \mathrm{C}$ in Water

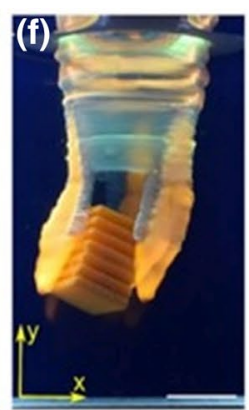

Lifted at $25^{\circ} \mathrm{C}$ in Water

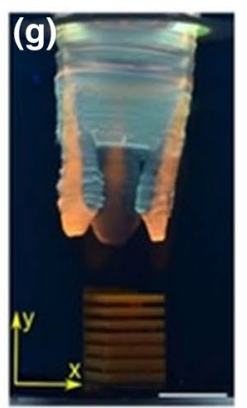

$50^{\circ} \mathrm{C}$ in Water
Fig. 6 Dual-shape change tubes. a Schematic of the basic anatomy of the coral polyp; the image was created based on encyclopedic depictions of the polyp. $50 \mathbf{b}, \mathbf{c}$ CAD model and image of a 3D printed and photocured tube with cylindrical base and three fingers. $\mathbf{d}-\mathbf{g}$ Optical snapshots of shape change of the tube at different temperatures. The

ink's elastic behaviour when the magnetic field is removed. By using direct-ink writing, McCracken et al. developed revolutionary iron oxide nanoparticle-loaded ionotropic hydrogels which are capable to actuate in the presence of local magnetic fields [166]. In order to characterize the proposed material, they printed various structures that mimic elementary dynamic/flexural features of Echinoderm and Cnidarian organisms, with a particular focus on the tentacle morphologies of sea jellies. Studies have shown that the devices have high mechanical toughness and flexibility, their structure remains intact in aqueous environments with shear and turbulent flow, but they can also move in different directions in response to stimuli while submerged. Another example was proposed by Wei et al. [167]. The authors have described an approach to constructing 4D printed stents with magnetoresponsive materials developed by direct-write printing of ultraviolet cross-linking PLA-based inks. The device could be guided magnetically to its destination.

Kirilova et al. [7] developed hollow self-folding tubes with an inner diameter of $20 \mu \mathrm{m}$, similar to small blood tube was suspended over a part placed in a tank. When water was added to the tank, the tube shows uniaxial elongation and gripping of the part. Upon heating to $50{ }^{\circ} \mathrm{C}$, the tube shortened and the fingers opened to release the part back to the bottom of the tank. Scale bars are $1 \mathrm{~cm} \mathrm{[159]}$

vessels based on 4D bioprinting of shape-morphing biopolymer hydrogels (Fig. 7). Their approach was based on simultaneous printing of polymer-cell bioinks, namely an alginate/hyaluronic acid hydrogel and mouse bone marrow stromal cells, which can differentiate into a variety of cell types in the presence of appropriate stimuli. Polymers have been previously modified with methacrylate groups to make them photo-crosslinkable. The results demonstrate that the printing process does not negatively affect the viability of the printed cells, and the printed tubes undergo cell survival for at least 7 days without any decrease in cell viability.

Taken together, the summarized examples demonstrate the enormous potential of $4 \mathrm{D}$ printing in the medical field. With increased research of multi-stimuli responsive materials and AM printing methods, a wide range of currently inconceivable applications may become available especially where personalized medical treatments are important. The most relevant biomedical applications related to both 3D and 4D printing technology will be briefly described in the next section.

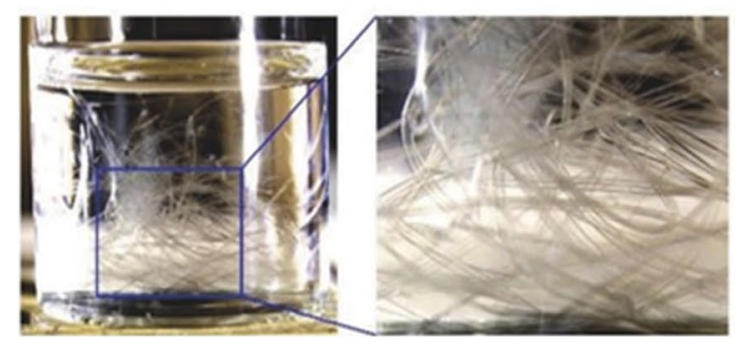

Fig. 7 Examples of the fabricated self-folding tubes (from right to left): schematic illustrations and representative microscope images of single tubes with/without printed cells formed through the described
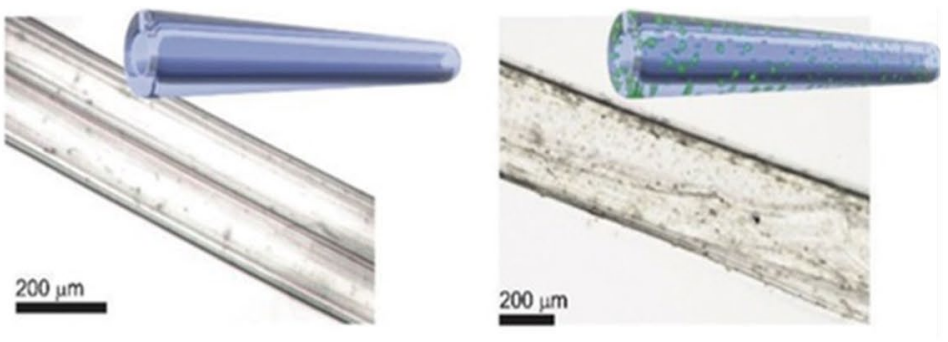

4D biofabrication process; photograph of a glass vial containing a large number of self-folded tubes, indicating on the possibility of their large-scale production [7] 


\section{Overview of Current Biomedical Applications}

AM technology contributes to a significant transformation of the medical field. It has now broad applications in drug delivery, tissue regeneration, chemotherapy and medical diagnosis. As mentioned above, there is a development from 3D to 4D materials especially in the medical device fabrication and self-assembling architectures that can emulate biological structures. Furthermore, there is a constant motivation towards individualized pharmacotherapy, and AM technology has opened the doors for customizing pharmaceutical dosage forms with multiple drugs, controlled chemistry, complex internal geometries and drug release profiles [2].

Using 3D/4D printing, a large variety of drug delivery systems can be developed with high accpuracy, such as tablets, capsules, multilayered drug delivery systems, nano-suspensions, orodispersible films, transdermal systems, wound healing patches, or vaginal and rectal delivery systems [169-173]. The most commonly used pharmaceutical active ingredients include steroidal antiinflammatory drugs, acetaminophen, caffeine, salicylic acid, antibiotics, paclitaxel, prednisolone, folic acid, insulin, captopril, curcumin etc. [2, 173]. Furthermore, the ink formulations have been obtained from a number of polymers, i.e. PLLA, PEG, PVAc, PEG, diacrylate, PVP, cellulose derivatives and others [2].

The main printing techniques used for drug development are inkjet printing and fused deposition modelling [174]. It is worth noting that Spritam ${ }^{\circledR}$ (an anti-epileptic seizure drug) by Aprecia Pharmaceuticals is the first drug manufactured-and currently the only one-using 3D printing technology that was approved by US Food and Drug Administration in 2015 [175]. The main advantage of this product is that it has an extremely porous structure that rapidly disintegrates in contact with liquids.

Moving a step further, the delivery of drugs through the skin could be the solution to a simple, self-administering, pain-free pharmaceutical therapy [176]. Recently, Wang et al. [177] designed aligned-fiber antibiotic (tetracycline hydrochloride) patches based on PCL, PVP and their composite system by using an EHD printing technique. They showed that the proposed technology enabled size, pore volume, drug loading and patch thickness control and has been successfully used to print 3D fibrous composite polymer-drug patches. A new direction of research is the use of micro-needles (MN) transdermal patches [178]. MN produces superficial pores into the skin to allow local permeation of the therapeutic substances. MN for insulin delivery with cone and pyramid geometries composed of a biocompatible resin has been recently developed. Moreover, a biodegradable MN based on PLA designed by Luzuriaga et al. [179] was able to penetrate the outer layers of the skin and release over time a small molecule drug.

A recent study by Malachowski [180] investigated a 4D printed thermo-responsive multi-fingered drug eluting device, referred to as 'theragrippers'. The theragrippers can be used to release drugs (mesalamine and doxorubicin were tested) in a controlled matter in the gastrointestinal tract and are based on poly(propylene fumarate) and poly( $\mathrm{N}$-isopropyl acrylamide-co-acrylic acid). The device can actuate above $32{ }^{\circ} \mathrm{C}$ allowing them to grip onto tissue when introduced from a cold state into the body.

In addition to individualized pharmacotherapy, technological advances are being made in terms of customized prosthetics and implants with heterogeneous and complex structure. Progress has been registered in the printing of stents [181], splints [182], contact lenses [183], bone implants [184, 185], cartilage or tendon implants [186], intrauterine contraceptive devices [187], as well as artificial skin [188], parts of the ear [189] and heart valves [190].

Personalized prostheses allow the restoration of mobility and function, as well as the normal appearance lost due to deformities or trauma so that patients can start rehabilitation and participate in daily activities. Partial finger prosthesis was recently developed by Young et al. [191] Authors have shown that AM technology can increase the production speed and reduce the production cost of upper limb prostheses. Another example was demonstrated by Alonso et al. [192] who prepared a polyvinyl alcohol and gelatine hydrogel reinforced with ceramics particles for applications in dentistry. 3D printing can also help patients recover from fractures or bone defects. The manufacturing of 3D-printed $\mathrm{PCL} / \beta$-tricalcium phosphate mandibular prosthesis was described by Park et al. [193]. TMSC were seeded into the scaffold and implanted in rabbits to evaluate effects in bone regeneration. The implanted material induced effective osteogenesis showing that the $3 \mathrm{D}$ prosthetic provides a good environment for bone attachment and regeneration.

As cell printing gained interest in biomedical engineering field, namely cellularized printed scaffolds for biomedical application, owing to ability of combining biocompatible materials, cells, and supportive components into printed constructs, researchers investigated the possibility to synthesise soft tissue bioprinting hydrogels [194]. A triblock copolymer PCL-PEG-PCL diacrylate, a single-component precursor network, was synthesized via ring-opening reaction and formed crosslinked hydrogel under visible-light exposure. To the PCL-PEG-PCL triblock copolymer diol, containing hydrophilic PEG segments and hydrophobic PCL segments, it was further added acryloyl groups, and the new network was reported as being highly elastic and excellent mechanical properties to be tuned to match various native soft tissues and for bio-printing various cells to form 
cell—gel constructs. Also, the hydrogels present good cell compatibility to support fibroblast growth in vitro.

$3 \mathrm{D} / 4 \mathrm{D}$ printing concepts have been exploited in chemical analysis, microorganism/biomolecule detection and separation, metabolites monitoring and diagnostics [195]. The clinical benefits of AM are also visible in the field of anatomical models for surgical planning and training. AM bio-models can be generated based on CT or MRI volumetric medical images [196]. This technology can improve the resolution and accuracy of surgical procedures by providing visual aid or tactile feedback. As a result, this can translate into reduced operating time, cost, and risks, especially when patients have deformities or anatomical abnormalities [197]. To date, anatomical replicas of various organs, such as kidney, heart, ureter, liver and even brain, have been beneficial for preoperative planning [198-200].

\section{Machine Learning in Additive Manufacturing}

The multitude of aspects solicited and necessarily imposed by the AM applications implies and enforces conditions and factors in relation to materials and processing techniques and which, in turn, bring a multitude of information that should be considered to improve the 3D-printing process. By gathering information involved in the key printing steps performed in AM, and by providing them to computerized systems, it is possible to intelligently achieve and pursue the objectives proposed by machine learning, a branch of artificial intelligence (a.i.), to improve the efficiency and performance of the available system in these areas, instead of following pre-programmed procedures. At the same time, data sets imply multiple variables and data analyses are complex, so modern computationally intensive methods become a useful tool for solving the grounds.

As shown in Dennis M. Dimiduk et al. review, drastic improvements have taken place last years, and are still evolving, in the fields of automated/autonomous data analysis, informatics, and deep learning [201]. The advancements come from the huge digital data, computing power, and algorithms applied to a.i. systems and then induced to ML. In the review, a distinction is made between the term ML, used for obtaining a computed model of complex non-linear relationships or complex patterns within data, and a.i. as a framework for making machine based decisions and actions using ML tools and analyses.

Practically, the current applications of ML in additive manufacturing are involved in improving the efficiency in the prefabrication stage and defect detection, while for nearterm are intended the real-time build control and predictive maintenance. At the same time, as it was stipulated in the Ying Zhang article, ML techniques have been used to represent inorganic materials [202], predict fundamental properties [203-205], create atomic potential, identify functional candidates [206, 207], analyze complex reaction networks, and guide experimental design [208-210].

Recent articles by Felix W. Baumann et al. [211], Micheal Omotayo Alabi et al. [212], Athmaja S. [213] and Dennis M. Dimiduk et al. [201], also analyze the machine learning trends in additive manufacturing, ML algorithms for big data analytics, recent applications of ML with big data in the AM industry, as well as the perspectives on the impact of ML, deep learning, and artificial intelligence on materials, processes, and structures engineering.

The general directions addressed within ML interconnected with the AM objectives are found in the specialized literature and illustrate the tasks and results obtained in this field (figure adapted from Felix W. Baumann et al. [201] review). The next figure illustrates the core concepts as pursued by Felix W. Baumann et al. among AM and ML and the relations and interdependence within and between these two domains for influencing the object preparation, as well as the process parameters, which ultimately determine the quality of the object.

At the same time, the following adapted figure (from the review by Felix W. Baumann et al. [211]) underlines the relationship between individual concepts found at the basis of ML applications to improve AM processes.

Machine learning can comprise $(*)$ a common application for materials selection based on predictions of future properties of unknown compounds, or discovering new ones, $(* *)$ tools for extracting greater and more accurate information from diagnosis, and $(* * *)$ instruments for the automation loop between diagnosis and synthesis, and

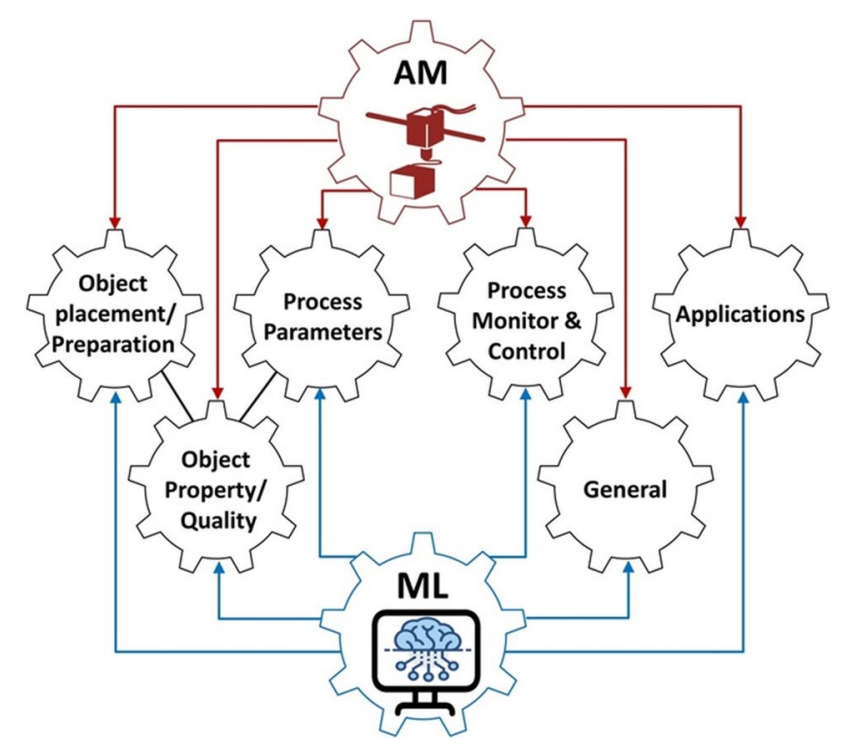

Fig. 8 The core concepts of AM and ML (adapted from Felix W. Baumann et al. [211]) 
reducing the degree of human intervention and reliance on heuristics [214, 215] [Fig. 8].

The development of QSARs, - which links measured properties to the compound chemical structure-and other models by which experimental data are deposited into mathematical algorithms, offers in the frame of the machine learning solutions for preparation of materials with good performance and predicted properties, even the discovery of new materials with potential of applicability in the AM field [136, 216-218] [Fig. 9].

Within the framework of "Advancing and accelerating materials innovation through the synergistic interaction among computation, experiment, and theory: opening new frontiers" workshop [219] and the MGI, whose ultimate goal is to bring products to market, six applicationfocused domains were identified as areas of importance: (i) materials for health and consumer applications, (ii) materials for information technologies, (iii) new functional materials, (iv) materials for efficient separation processes, (v) materials for energy and catalysis, and (vi) multicomponent materials and additive manufacturing [220].

All these areas, including those of multicomponent materials and additive manufacturing, comprise polymers owing to their structural and functional characteristics, and highly tunable physical, chemical, and electrical properties. In this context, there is an imperative necessity for predictive models to guide the development of processing parameters and enable control of the structure and defects in 3D printing of polymers, to create hierarchical 3D structures with predictive behavior related to their microstructure and interfaces, and characterization methods to conclude about the behavior of the macromolecular chains at interfaces leading to crosslinked networks and strengthening of the complex three dimensional structures as they are produced [221-229].

\section{Future Directions and Challenges}

Even though AM offer unparalleled flexibility in designing materials over traditional manufacturing methods, there are several limitations that can hinder the progression to market. These include the impossibility to print large volumes of materials, slow print times, limited material availability, inaccurate actuation, high-cost printers, and there is no possibility to print more materials on the same printer. For bioprinting, it is essential to further develop in-depth and complex in vitro and in vivo studies assessing efficacy, and safety. More importantly, there is only one AM product approved by the FDA on the medical market. The main obstacles can be found in the lack of regulation and control standards for the additive manufactured medical devices. However, regulatory requirements are hard to implement, mainly due to the variability of AM methods. Taking into account all the techniques and materials currently available, there is no possibility to provide a universal set of guidelines for all printing methods. Furthermore, although the studies highlighted in this review are certainly innovative and may form the basis of future medical devices, follow-up studies that use and in-depth characterize the applied concepts are generally not pursued. So far, for example, reports that demonstrate the performance of an implanted device made by using the AM technology remain scarce. Few materials present complex geometries and elastic properties that mimic the human tissue. Moreover, studies that demonstrate the application of these research efforts in a clinical context have hardly been published. These are the main current limitations of AM applicable to the biomedical field that companies and researchers are trying to solve in order to produce devices in predictive and reproductive ways.

Despite these limitations and uncertainties, one clear thing is that this technology is still in an early development phase as a research area. We envisaged that due to the promising features demonstrated so far, an unexpected multitude of unexplored research areas and disciplines will benefit

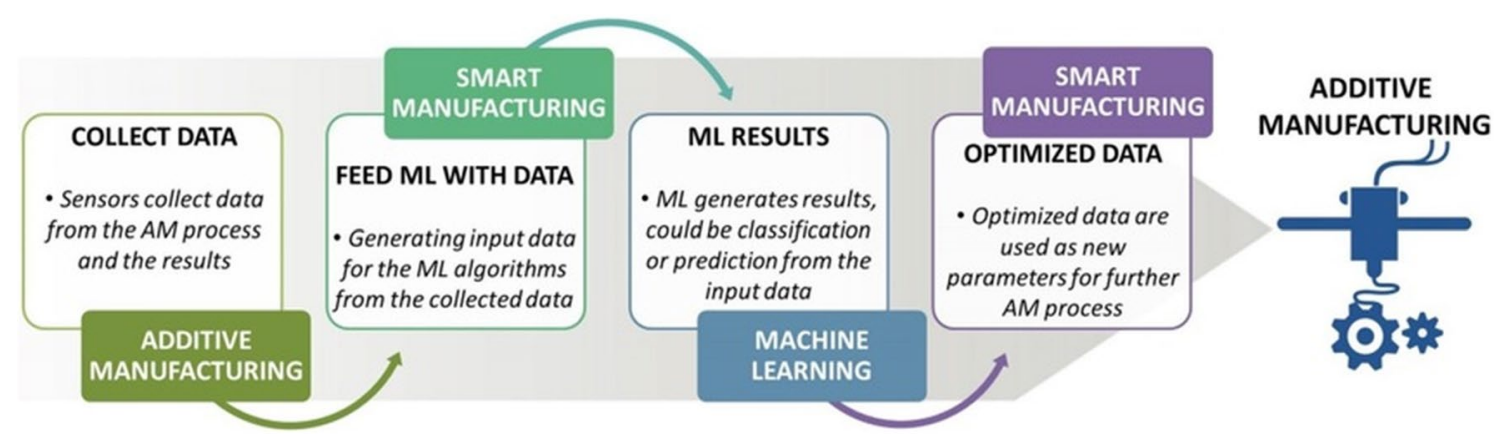

Fig. 9 The relationship between ML and AM processes. (adapted from Felix W. Baumann et al. [211]) 
from the innovations of 3D printing, spanning from medicine to robotics, energy technologies, biotechnology, and food production. In the coming years, a quantitative increase will also be recorded in the development of high-performance printers, a good example being the 5D technology. Five-axis 3D printing is currently of high interest because it addresses some of the challenges associated with regular 3D printing. Thus, due to its ability to build an object from several directions, stronger parts can be produced. Multi-material printers will also be developed. The investments in this area will further lead to innovations in high-performance biocompatible materials. A strong emphasis on personalization and individualization will also be pursued.

We also believe that the printing technology will soon be readily available to the general public, the cost of 3D printers will decrease and more objects developed through CAD will be accessible from the online platforms. This will have a profound effect on the manufacturing businesses, but also on the society that asks for new strategies, innovations and policies alike.

\section{Conclusions}

In the health sector, 3D/4D printing can generate efficiency, create innovative products, improve the quality of medical performance, and reduce costs and production risks. This technology has grown enormously in the manufacture of new drug formulations, implants, personalized prostheses, advanced diagnostics, biosensor based feedback devices, and bioprinting of human tissues and organs and has demonstrated that it has the ability to play a key role in the progressive development of new materials. Furthermore, it seems that AM technology is turning into a multidisciplinary field that will require scientists to become knowledgeable outside of their main field of study, including biology, material science, and chemistry. Ultimately, these early successes can hope to provide a future in which medical treatments can become highly personalized with patient-specific treatments, but there are many areas that require further development before the impact of AM technology can be fully evaluated.

Acknowledgements This work was financially supported by the grant of the Romanian National Authority for Scientific Research, CNCSUEFISCDI, project number PN-III-P1-1.1-PD-2016-0685 "Biodegradable nanostructured hydrogels as therapeutic delivery systems for skin tissue remodeling", within PNCDI III.

Author Contributions The individual contributions of authors are as follows: AG: conceived the study, and participated in its design, and helped to draft the manuscript; APC: helped to draft and revise the manuscript; LEN: participated in the design of the study; AGR: contributed to the overview of current biomedical applications chapter and helped to revise the manuscript; IN: carried out the revision of the manuscript; VMC: carried out the "Machine learning in additive manufacturing" chapter.

Funding All sources of funding for the research reported were declared.

Research Involving Human Participants Manuscript does not reports studies involving human participants, human data or human tissue must.

\section{References}

1. Douroumis D (2019) 3D printing of pharmaceutical and medical applications: a new era. Pharm Res 36(3):41-42

2. Jamróz W, Szafraniec J, Kurek M, Jachowicz R (2018) 3D printing in pharmaceutical and medical applications: recent achievements and challenges. Pharm Res 35(9):176:1-22

3. De Mori A, Peña Fernández M, Blunn G, Tozzi G, Roldo M (2018) 3D printing and electrospinning of composite hydrogels for cartilage and bone tissue engineering. Polymers 10(3):285:1-26

4. Gopinathan J, Noh I (2018) Recent trends in bioinks for 3D printing. Biomater Res 22(1):1-15

5. Albanna M, Binder K, Murphy S, Kim J, Qasem S, Zhao W (2019) In situ bioprinting of autologous skin cells accelerates wound healing of extensive excisional full-thickness wounds. Sci Rep 9(1):1-15

6. Ding H, Chang R (2018) Simulating image-guided in situ bioprinting of a skin graft onto a phantom burn wound bed. Addit Manuf 22:708-719

7. Kirillova A, Maxson R, Stoychev G, Gomillion C, Ionov L (2017) 4D biofabrication using shape-morphing hydrogels. Adv Mater 29(46):1-8

8. Hölzl K, Lin S, Tytgat L, Van Vlierberghe S, Gu L, Ovsianikov A (2016) Bioink properties before, during and after 3D bioprinting. Biofabrication 8(3):032002

9. Derakhshanfar S, Mbeleck R, Xu K, Zhang X, Zhong W, Xing M (2018) 3D bioprinting for biomedical devices and tissue engineering: a review of recent trends and advances. Bioact Mater 3(2):144-156

10. Invernizzi M, Turri S, Levi M, Suriano R (2018) 4D printed thermally activated self-healing and shape memory polycaprolactone-based polymers. Eur Polym J 101:169-176

11. Gao B, Yang Q, Zhao X, Jin G, Ma Y, Xu F (2016) 4D bioprinting for biomedical applications. Trends in Biotechnol 34(9):746-756

12. Wu J, Huang L, Zhao Q, Xie T (2017) 4D printing: history and recent progress. Chinese J Polym Sci 36(5):563-575

13. Javaid M, Haleem A. 4D printing applications in medical field: a brief review. (2018) Clinical Epidemiology and Global Health

14. Miao S, Castro N, Nowicki M, Xia L, Cui H, Zhou X, Zhang LG (2017) 4D printing of polymeric materials for tissue and organ regeneration. Mater Today 20(10):577-591

15. Tibbits S. 4D printing: multi-material shape change. (2014) Architect Design. 84(1):116-121

16. Studart AR (2016) Additive manufacturing of biologicallyinspired materials. Chem Soc Rev 45(2):359-376

17. Khan F, Celik HK, Oral O (2018) A Short Review on 4D Printing. 3rd International Congress on 3DpPrinting (additive manufacturing) technologies and digital industry. Çetinkaya K, Özsoy K, Duman B, Kayaalp K, editors. Antalya, Turkey, 199-203 
18. Yang G, Yeo M, Koo Y, Kim G (2019) 4D bioprinting: technological advances in biofabrication. Macromol Biosci 19(5): 1800441

19. Kumar P, Tech M, Roy S, Hegde H, Bharti S, Kumar (2019) 4D and 5D Printing: Healthcare's New Edge, In: Ahmad N, Gopinath P, Dutta R (eds) 3D Printing Technology in Nanomedicine., 143-163

20. Haleem A, Javaid M, Vaishya R (2019) 5D printing and its expected applications in Orthopaedics. J Clin Orthop Trauma 10(4):809-810

21. Ligon SC, Liska R, Stampfl J, Gurr M, Mülhaupt R (2017) Polymers for 3D printing and customized additive manufacturing. Chem Rev 117:10212-10290

22. Zhang Z, Demir KG, Gu GX (2019) Developments in 4D-printing: a review on current smart materials, technologies, and applications. Int J Smart Nano Mater 10(3):205-224

23. Pei E, Loh GH (2018) Technological considerations for 4D printing: an overview. Progr Addit Manuf 3:95-107

24. Nadgorny M, Ameli A (2018) Functional polymers and nanocomposites for 3D printing of smart structures and devices. ACS Appl Mater Interfaces 10:17489-17507

25. Fink JK (2019) 3D industrial printing with polymers. John Wiley \& Sons, Inc., River Street

26. Izdebska J, Thomas S (2016) Printing on polymers: fundamentals and applications. Elsevier Inc, Oxford

27. Teoh S, Goh B, Lim J (2019) 3D printed polycaprolactone scaffolds for bone regeneration-success and future perspective. Tissue Eng Part A 25:931-935

28. Mastro PF (2016) Plastics product design, ISBN-13: 978-1118842713\$4

29. Bourell D, Kruth JP, Leu M, Levy G, Rosen D, Beese AM, Clare A (2017) Materials for additive manufacturing. CIRP Ann Manuf Technol 66:659-681

30. Truby RL, Lewis JA (2016) Printing soft matter in three dimensions. Nature 540(7633):371-378

31. Mamoshina P, Vieira A, Putin E, Zhavoronkov A (2016) Applications of deep learning in biomedicine. Mol Pharm 13(5):1445-1454

32. Ghidini T (2018) Regenerative medicine and 3D bioprinting for human space exploration and planet colonisation. J Thorac Dis 10(S20):S2363-S2375

33. de Azevedo Gonçalves Mota RC, da Silva EO, de Lima FF, de Menezes LR, Thiele A (2016) 3D printed scaffolds as a new perspective for bone tissue regeneration: literature review. Mater Sci Appl 7(8):430-452

34. Ong C, Nam L, Ong K, Krishnan A, Huang C, Fukunishi T (2018) 3D and 4D bioprinting of the myocardium: current approaches, challenges, and future prospects. BioMed Res Int. 2018:1-11

35. Khan FA, Celik HK, Oral O, Rennie AEW (2018) A short review on 4d printing. Int J Print Technol Digit Ind 2(2):59-67

36. Lebel L, Aissa B, Khakani M, Therriault D (2010) Ultravioletassisted direct-write fabrication of carbon nanotube/polymer nanocomposite microcoils. Adv Mater 22(5):592-596

37. Guo SZ, Gosselin F, Guerin N, Lanouette AM, Heuzey MC, Therriault D (2013) Solvent cast three-dimensional printing of multifunctional microsystems. Small 9(24):4118-4122 9)

38. Khoo Z, Teoh J, Liu Y, Chua C, Yang S, An J (2015) 3D printing of smart materials: a review on recent progresses in 4D printing. Virtual Phys Prototyp 10(3):103-122

39. Whitford W, Hoying J (2016) A bioink by any other name: terms, concepts and constructions related to 3D bioprinting. Future Sci OA 2(3):FSO133

40. Stanton M, Samitier J, Sánchez S (2015) Bioprinting of 3D hydrogels. Lab Chip 15(15):3111-3115
41. He Y, Yang F, Zhao H, Gao Q, Xia B, Fu J (2016) Research on the printability of hydrogels in 3D bioprinting. Sci Rep. 6(1)

42. Ortiz-Acosta D, Moore T (2018) Functional 3D printed polymeric materials. IntechOpen, Functional Materials

43. Serra T, Mateos-Timoneda M, Planell J, Navarro M (2013) 3D printed PLA-based scaffolds. Organogenesis 9(4):239-244

44. Zhou J, Sheiko SS (2016) Reversible shape-shifting in polymeric materials. J Polym Sci B Polym Phys 54:1365-1380

45. Momeni F, Seyed M, Mehdi Hassani N, Liu X, Ni J (2017) A review of 4D printing. Mater Design 122:42-79

46. Nkomo N (2018) A review of $4 \mathrm{D}$ printing technology and future trends, 11th South African Conference on computational and applied mechanics

47. Li Y, Zhang Y, Akpek A, Shin S, Khademhosseini A (2016) 4D bioprinting: the next-generation technology for biofabrication enabled by stimuli-responsive materials. Biofabrication 9(1):012001

48. Liu J, Sun L, Xu W, Wang Q, Yu S, Sun J (2019) Current advances and future perspectives of $3 \mathrm{D}$ printing natural-derived biopolymers. Carbohydr Polym 207:297-316

49. Carrow JK, Kerativitayanan P, Jaiswal MK, Lokhande G, Gaharwar AK (2015) Polymers for bioprinting in essentials of 3D biofabrication and translation. 229-248

50. Neamtu I, Chiriac AP, Nita LE, Diaconu A, Rusu AG (2019) Nanogels containing polysaccharides for bioapplications In: Vasile C (ed). Polymeric Nanomaterials in Nanotherapeutics

51. Naghieh S, Sarker M, Abelseth E, Chen X (2019) Indirect 3D bioprinting and characterization of alginate scaffolds for potential nerve tissue engineering applications. J Mech Behav Biomed Mater 93:183-193

52. Sarker M, Naghieh S, McInnes A, Ning L, Schreyer D, Chen X (2019) Bio-fabrication of peptide-modified alginate scaffolds: printability, mechanical stability and neurite outgrowth assessments. Bioprinting 14:e00045

53. Lewicki J, Bergman J, Kerins C, Hermanson O (2019) Optimization of 3D bioprinting of human neuroblastoma cells using sodium alginate hydrogel. Bioprinting.:e00053

54. Wei X, Luo Y, Huang P (2019) 3D bioprinting of alginate scaffolds with controlled micropores by leaching of recrystallized salts. Polym Bull 1-12

55. Duin S, Schütz K, Ahlfeld T, Lehmann S, Lode A, Ludwig B (2019) 3D bioprinting of functional Islets of Langerhans in an alginate/methylcellulose hydrogel blend. Adv Healthc Mater 8(7): 1801631

56. Heggset E, Strand B, Sundby K, Simon S, Chinga-Carrasco G, Syverud K (2018) Viscoelastic properties of nanocellulose based inks for 3D printing and mechanical properties of $\mathrm{CNF} /$ alginate biocomposite gels. Cellulose 26(1):581-595

57. Seok J, Oh S, Lee S, Lee J, Kim W, Park S (2019) Fabrication and characterization of 3D scaffolds made from blends of sodium alginate and poly(vinyl alcohol). Mater Today Commun 19:56-61

58. Jia W, Gungor-Ozkerim P, Zhang Y, Yue K, Zhu K, Liu W (2016) Direct 3D bioprinting of perfusable vascular constructs using a blend bioink. Biomaterials 106:58-68

59. Liu Q, Li Q, Xu S, Zheng Q, Cao X (2018) Preparation and properties of 3D printed alginate-chitosan polyion complex hydrogels for tissue engineering. Polymers 10(6):664

60. Datta S, Sarkar R, Vyas V, Bhutoria S, Barui A, Roy Chowdhury A (2018) Alginate-honey bioinks with improved cell responses for applications as bioprinted tissue engineered constructs. j Mater Res Technol 33(14):2029-2039

61. Wang X, Tolba E, Schröder HC, Neufurth M, Feng Q, DiehlSeifert B, Müller WE (2014) Effect of bioglass on growth and biomineralization of SaOS-2 cells in hydrogel after 3D cell bioprinting. PLoS One 9(11):e112497 
62. Wu J, Miao G, Zheng Z, Li Z, Ren W, Wu C (2018) 3D printing mesoporous bioactive glass/sodium alginate/gelatin sustained release scaffolds for bone repair. J Biomater Appl 33(6):755-765

63. Diaconu A, Nita LE, Bercea M, Chiriac AP, Rusu AG, Rusu D (2017) Hyaluronic acid gels with tunable properties by conjugating with a synthetic copolymer. Biochem Eng J 125:135-143

64. Chiriac AP, Nita LE, Diaconu A, Bercea M, Tudorachi N, Pamfil D (2017) Hybrid gels by conjugation of hyaluronic acid with poly(itaconic anhydride-co-3,9-divinyl-2,4,8,10-tetraoxaspiro (5.5)undecane) copolymers. Int J Biol Macromol 98:407-418

65. Highley C, Prestwich G, Burdick J (2016) Recent advances in hyaluronic acid hydrogels for biomedical applications. Curr Opin Biotechnol 40:35-40

66. Noh I, Kim N, Tran HN, Lee J, Lee C (2019) 3D printable hyaluronic acid-based hydrogel for its potential application as a bioink in tissue engineering. Biomater Res 23(3):1-9

67. Law N, Doney B, Glover H, Qin Y, Aman Z, Sercombe T (2018) Characterisation of hyaluronic acid methylcellulose hydrogels for 3D bioprinting. J Mech Behav Biomed Mater 77:389-399

68. Thomas R, Vu P, Modi S, Chung P, Landis R, Khaing Z (2017) Sacrificial crystal templated hyaluronic acid hydrogels as biomimetic 3D tissue scaffolds for nerve tissue regeneration. ACs Biomater-Sci Eng 3(7):1451-1459

69. Włodarczyk-Biegun M, del Campo A (2017) 3D bioprinting of structural proteins. Biomaterials 134:180-201

70. Nistor M, Chiriac AP, Nita LE, Vasile C (2013) Characterization of the semi-interpenetrated network based on collagen and poly(N-isopropyl acrylamide-co-diethylene glycol diacrylate). Int J Pharm 452(1-2):92-101

71. Li Q, Lei X, Wang X, Cai Z, Lyu P, Zhang G (2019) Hydroxyapatite/collagen three-dimensional printed scaffolds and their osteogenic effects on human bone marrow-derived mesenchymal stem cells. Tissue Engineering Part A

72. Diamantides N, Wang L, Pruiksma T, Siemiatkoski J, Dugopolski C, Shortkroff S (2017) Correlating rheological properties and printability of collagen bioinks: the effects of riboflavin photocrosslinking and $\mathrm{pH}$. Biofabrication 9(3):034102

73. Yang X, Lu Z, Wu H, Li W, Zheng L, Zhao J (2018) Collagenalginate as bioink for three-dimensional (3D) cell printing based cartilage tissue engineering. Mater Sci Eng C 83:195-201

74. Lee J, Yeo M, Kim W, Koo Y, Kim GH (2018) Development of a tannic acid cross-linking process for obtaining 3D porous cellladen collagen structure. Int J Biol Macromol 110:497-503

75. Marques C, Diogo G, Pina S, Oliveira J, Silva T, Reis R (2019) Collagen-based bioinks for hard tissue engineering applications: a comprehensive review. J. Mater. Sci.: Mater. Med. 30 (3)

76. Sun Y, Yang C, Zhu X, Wang J, Liu X, Yang X (2019) 3D printing collagen/chitosan scaffold ameliorated axon regeneration and neurological recovery after spinal cord injury. J Biomed Mater Res A 107(9):1898-1908

77. Rusu AG, Chiriac AP, Nita LE, Bercea M, Tudorachi N, Ghilan A, Pamfil D, Rusu D, Cojocaru FD (2019) Interpenetrated polymer network with modified chitosan in composition and selfhealing properties. Int J Biol Macromol 132:374-384

78. Rusu AG, Popa MI, Ibanescu C, Danu M, Verestiuc L (2016) Tailoring the properties of chitosan-poly(acrylic acid) based hydrogels by hydrophobic monomer incorporation. Mater Lett 164:320-324

79. Wu Q, Maire M, Lerouge S, Therriault D, Heuzey M (2017) 3D printing of microstructured and stretchable chitosan hydrogel for guided cell growth. Adv Biosyst 1(6):1700058

80. Yang Y, Chu L, Yang S, Zhang H, Qin L, Guillaume O (2018) Dual-functional 3D-printed composite scaffold for inhibiting bacterial infection and promoting bone regeneration in infected bone defect models. Acta Biomater 79:265-275
81. Ramirez Caballero S, Elsayed H, Tadier S, Montembault A, Maire E, David L (2019) Fabrication and characterization of hardystonite-chitosan biocomposite scaffolds. Ceram Int 45(7):8804-8814

82. Zhang J, Allardyce B, Rajkhowa R, Zhao Y, Dilley R, Redmond S (2018) 3D printing of slik particle-reinforced chitosan hydrogel structures and their properties. ACS Biomater Sci Eng 4(8):3036-3046

83. Wang J, Nor Hidayah Z, Razak S, Kadir M, Nayan N, Li Y (2018) Surface entrapment of chitosan on 3D printed polylactic acid scaffold and its biomimetic growth of hydroxyapatite. Compos Interfaces 26(5):1465-478

84. Ramirez Caballero S, Saiz E, Montembault A, Tadier S, Maire E, David L (2018) 3-D printing of chitosan-calcium phosphate inks: rheology, interactions and characterization. J Mater Sci-Mater M. $30(1)$

85. Guerra A, Ciurana J (2018) 3D-printed bioabsordable polycaprolactone stent: the effect of process parameters on its physical features. Mater Des 137:430-437

86. Guerra A, Cano P, Rabionet M, Puigm T, Ciuranam J (2018) Effects of different sterilization processes on the properties of a novel 3D-printed polycaprolactone stent. Polym Adv Technol 29(8):2327-2335

87. Guerra A, Cano P, Rabionet M, Puig T, Ciurana J (2018) 3D-printed PCL/PLA composite stents: towards a new solution to cardiovascular problems. Materials 11(9):1679

88. Park Jongsung (2017) 3D-printed biodegradable polymeric stent integrated with a battery-less pressure sensor for biomedical applications.19th International Conference on Solid-State Sensors. Actuat Microsyst (Transducers). 47-50

89. Neamtu I, Chiriac AP, Diaconu A, Nita LE, Balan V, Nistor MT (2014) Current concepts on cardiovascular stent devices. Mini Rev Med Chem 14(6):505-536

90. Li X, Cui R, Sun L, Aifantis K, Fan Y, Feng Q (2014) 3D-Printed Biopolymers for Tissue Engineering Application. Int J Polym Sci 2014:1-13

91. Sundaramurthi D, Rauf S, Hauser C (2016) 3D bioprinting technology for regenerative medicine applications. Int J Bioprint 2(2): $9-26$

92. Jang C, Lee J, Kim G (2019) Synergistic effect of alginate/ BMP-2/umbilical cord serum-coated on 3D-printed PCL biocomposite for mastoid obliteration model. J Ind Eng Chem 72:432-441

93. Bae S, Lee K, Park J, Lee J, Jung C, Yu J (2018) 3D bioprinted artificial trachea with epithelial cells and chondrogenic-differentiated bone marrow-derived mesenchymal stem cells. Int J Mol Sci 19(6): 1624

94. Park S, Lee S, Seok J, Lee J, Kim W, Kwon I (2018) Fabrication of 3D printed PCL/PEG polyblend scaffold using rapid prototyping system for bone tissue engineering application. J Bionic Eng 15(3):435-442

95. Peng C, Zheng J, Chen D, Zhang X, Deng L, Chen Z (2018) Response of hPDLSCs on 3D printed PCL/PLGA composite scaffolds in vitro. Mol Med Rep 18(2):1335-1344

96. Ma J, Lin L, Zuo Y, Zou Q, Ren X, Li J (2019) Modification of 3D printed PCL scaffolds by PVAc and HA to enhance cytocompatibility and osteogenesis. RSC Adv 9(10):5338-5346

97. Serra T, Planell JA, Navarro M (2013) High-resolution PLAbased composite scaffolds via 3-D printing technology. Acta Biomater 9(3):5521-5530 n. )

98. Subramaniam SR, Samykano M, Selvamani SK, Ngui WK, Kadirgama K, Sudhakar K, Idris MS (2019) 3D printing: overview of PLA progress AIP Conference Proceedings 2059, 020015

99. Kuhnert I, Corer Y, Harald Brunig H, An Tran N (2018) Processing of poly(lactic acid). Adv Polym Sci 282:1-34 
100. Giordano R, Wu B, Borland S, Cima L, Sachs E, Cima M (1997) Mechanical properties of dense polylactic acid structures fabricated by three dimensional printing. Journal of Biomaterials Science Polymer Edition 8(1):63-75

101. Kandasamy J (2018) A case study of 3D printed PLA and Its mechanical properties. Mater Today Proc. 5(2):11219-11226

102. Aveen KP, Vishwanath Bhajathari F, Jambagi Sudhakar C (2018) 3D printing \& mechanical characteristion of polylactic aid and bronze filled polylactic acid components. IOP Conference Series: Mater Sci Eng. 376: 012042

103. Valerga A, Batista M, Fernandez-Vidal S, Gamez A (2019) Impact of chemical post-processing in fused deposition modelling (FDM) on polylactic acid (PLA). Surf Qual Struct Polym 11(3):566

104. Kao C, Lin C, Chen Y, Yeh C, Fang H, Shie M (2015) Poly(dopamine) coating of 3D printed poly(lactic acid) scaffolds for bone tissue engineering. Mater Sci Eng C 56:165-173

105. Ryu J, Messersmith P, Lee H (2018) Polydopamine surface chemistry: a decade of discovery. ACS Appl Mater Interfaces 10(9):7523-7540

106. Yeh C, Chen Y, Shie M, Fang H (2015) Poly(dopamine)-assisted immobilization of Xu Duan on 3D printed poly(lactic acid) scaffolds to up-regulate osteogenic and angiogenic markers of bone marrow stem cells. Materials 8(7):4299-4315

107. Jaidev L, Chatterjee K (2019) Surface functionalization of 3D printed polymer scaffolds to augment stem cell response. Mater Des 161:44-54

108. Wang M, Favi P, Cheng X, Golshan N, Ziemer K, Keidar M (2016) Cold atmospheric plasma (CAP) surface nanomodified $3 \mathrm{D}$ printed polylactic acid (PLA) scaffolds for bone regeneration. Acta Biomater 46:256-265

109. Fu S, Zhang P (2019) Surface modification of polylactic acid (PLA) and polyglycolic acid (PGA) monofilaments via the cold plasma method for acupoint catgut-embedding therapy applications. Text Res J. 1: 004051751882484

110. Baran E, Erbil H (2019) Surface modification of 3D printed PLA objects by fused deposition modeling: a review J Colloid Interface Sci 3(2):43

111. Williams JK, Yoo J, Atala A (2019) Regenerative medicine approaches for tissue engineered heart valves, In: principles of regenerative medicine (Third Edition), 1041-1058

112. Kankala R, Xu X, Liu C, Chen A, Wang S (2018) 3D-printing of microfibrous porous scaffolds based on hybrid approaches for bone tissue engineering. Polymers 10(7):807

113. Lai Y, Li Y, Cao H, Long J, Wang X, Li L (2019) Osteogenic magnesium incorporated into PLGA/TCP porous scaffold by 3D printing for repairing challenging bone defect. Biomaterials 197:207-219

114. Chen H, Zhong J, Wang J, Huang R, Qiao X, Wang H, Tan Z (2019) Enhanced growth and differentiation of myoblast cells grown on E-jet 3D printed platforms. Int $\mathrm{J}$ Nanomedicine 14:937-950

115. Xin S, Chimene D, Garza J, Gaharwar A, Alge D (2019) Clickable PEG hydrogel microspheres as building blocks for 3D bioprinting. Biomater Sci 7(3):1179-1187

116. Kwak H, Shin S, Lee H, Hyun J (2019) Formation of a keratin layer with silk fibroin-polyethylene glycol composite hydrogel fabricated by digital light processing 3D printing. J Ind Eng Chem 72:232-240

117. Wang X, Jiang M, Zhou Z, Gou J, Hui D (2017) 3D printing of polymer matrix composites: a review and prospective. Compos B Eng 110:442-458

118. Kalsoom U, Nesterenko P, Paull B (2016) Recent developments in 3D printable composite materials. RSC Advances 6(65):60355-60371
119. Jang T, Jung H, Pan H, Han W, Chen S, Song J (2018) 3D printing of hydrogel composite systems: Recent advances in technology for tissue engineering. Int J Bioprint. 4(1)

120. Naranjo-Lozada J, Ahuett-Garza H, Orta-Castañón P, Verbeeten W, Sáiz-González D (2019) Tensile properties and failure behavior of chopped and continuous carbon fiber composites produced by additive manufacturing. Addit Manuf 26:227-241

121. Al Abadi H, Thai H, Paton-Cole V, Patel V (2018) Elastic properties of 3D printed fibre-reinforced structures. Compos Struct 193:8-18

122. Martin J, Fiore B, Erb R (2015) Designing bioinspired composite reinforcement architectures via 3D magnetic printing. Nat Commun. 6(1)

123. Campbell T, Ivanova O (2013) 3D printing of multifunctional nanocomposites. Nano Today 8(2):119-120

124. Ghilan A, Chiriac AP, Neamtu I, Nita LE (2019) Magnetic polymeric Nanocomposites. In: Vasile C, editor. Polymeric nanomaterials in nanotherapeutics

125. Zhang J, Zhao S, Zhu M, Zhu Y, Zhang Y, Liu Z (2014) 3D-printed magnetic Fe3O4/MBG/PCL composite scaffolds with multifunctionality of bone regeneration, local anticancer drug delivery and hyperthermia. J Mater Chem B 2(43):7583-7595

126. Rasoulianboroujeni M, Fahimipour F, Shah P, Khoshroo K, Tahriri M, Eslami H (2019) Development of 3D-printed PLGA/ $\mathrm{TiO} 2$ nanocomposite scaffolds for bone tissue engineering applications. Mater Sci Eng C 96:105-113

127. Oladapo B, Zahedi S, Adeoye A (2019) 3D printing of bone scaffolds with hybrid biomaterials. Compos Part B-Eng 158:428-436

128. Cho Y, Choi S, Lee S, Kim K, Cho Y (2019) Assessments of polycaprolactone/hydroxyapatite composite scaffold with enhanced biomimetic mineralization by exposure to hydroxyapatite via a 3D-printing system and alkaline erosion. Eur Polym J 113:340-348

129. Sydney Gladman A, Matsumoto EA, Nuzzo RG, Mahadevan L, Lewis JA (2016) Biomimetic 4D printing. Nature Materials 15(4):413-418

130. Jeon H, Lee M, Yun S, Kang D, Park K, Choi S (2019) Fabrication and characterization of 3D-printed biocomposite scaffolds based on PCL and silanated silica particles for bone tissue regeneration. Chem Eng J 360:519-530

131. Liu D, Nie W, Li D, Wang W, Zheng L, Zhang J, He C (2019) $3 \mathrm{D}$ printed PCL/SrHA scaffold for enhanced bone regeneration. Chem Eng J 362:269-279

132. Han X, Yang YD. Spintzyk C, Scheideler S, Li L P (2019) Carbon fiber reinforced PEEK composites based on 3D-printing technology for orthopedic and dental applications. J Clin Med $8(2): 240$

133. Zhang Y, Yu W, Ba Z, Cui S, Wei J, Li H (2018) 3D-printed scaffolds of mesoporous bioglass/gliadin/polycaprolactone ternary composite for enhancement of compressive strength, degradability, cell responses and new bone tissue ingrowth. Int J Nanomed 13:5433-5447

134. Habib A, Khoda B (2019) Development of clay based novel hybrid bio-ink for 3D bio-printing process.J Manuf Process 38:76-87

135. Urruela-Barrios R, Ramírez-Cedillo E, Díaz de León A, Alvarez A, Ortega-Lara W (2019) Alginate/gelatin hydrogels reinforced with $\mathrm{TiO} 2$ and $\beta$-TCP rabricated by microextrusion-based printing for tissue regeneration. Polymers 11(3):457

136. Bas O, Hanßke F, Lim J, Ravichandran A, Kemnitz E, Teoh S (2019) Tuning mechanical reinforcement and bioactivity of 3D printed ternary nanocomposites by interfacial peptide-polymer conjugates. Biofabrication 11(3):035028

137. Deng Z, Hu T, Lei Q, He J, Ma P, Guo B (2019) Stimuliresponsive conductive nanocomposite hydrogels with high 
stretchability, self-healing, adhesiveness, and 3D printability for human motion sensing. ACS Appl Mater Interfaces 11(7):6796-6808

138. McCracken J, Rauzan B, Kjellman J, Kandel M, Liu Y, Badea A (2018) 3D-printed hydrogel composites for predictive temporal (4D) cellular organizations and patterned biogenic mineralization. Adv Healthc Mater 8(1):1800788

139. Tao J, Zhang J, Du T, Xu X, Deng X, Chen S (2019) Rapid $3 \mathrm{D}$ printing of functional nanoparticle-enhanced conduits for effective nerve repair. Acta Biomater 90:49-59

140. Celikkin N, Mastrogiacomo S, Walboomers X, Swieszkowski W (2019) Enhancing X-ray attenuation of 3D printed gelatin methacrylate (GelMA) hydrogels utilizing gold nanoparticles for bone tissue engineering applications. Polymers 11(2):367

141. Löwa N, Fabert J, Gutkelch D, Paysen H, Kosch O, Wiekhorst F (2019) 3D-printing of novel magnetic composites based on magnetic nanoparticles and photopolymers. J Magn Magn Mater 469:456-460

142. Dizon J, Chen Q, Valino A, Advincula R (2018) Thermomechanical and swelling properties of three-dimensionalprinted poly (ethylene glycol) diacrylate/silica nanocomposites. MRS Commun 9(01):209-217

143. Nonato R, Mei L, Bonse B, Chinaglia E, Morales A (2019) Nanocomposites of PLA containing ZnO nanofibers made by solvent cast 3D printing: production and characterization. Eur Polym J 114:271-278

144. Chen R, Huang C, Hsu S (2019) Composites of waterborne polyurethane and cellulose nanofibers for $3 \mathrm{D}$ printing and bioapplications. Carbohydr Polym 212:75-88

145. Hockaday L, Kang K, Colangelo N, Cheung P, Duan B, Malone E (2012) Rapid 3D printing of anatomically accurate and mechanically heterogeneous aortic valve hydrogel scaffolds. Biofabrication 4(3):035005

146. Hong S, Sycks D, Chan H, Lin S, Lopez G, Guilak F (2015) 3D Printing: 3D printing of highly stretchable and tough hydrogels into complex, cellularized structures (Adv. Mater. 27/2015). Adv Mater. 27(27): 4034-4034

147. Tabriz A, Hermida M, Leslie N, Shu W (2015) Three-dimensional bioprinting of complex cell laden alginate hydrogel structures. Biofabrication 7(4):045012

148. Park H, Lee J, Jung H, Kim D, Kim S, Sultan M (2018) An omentum-cultured 3D-printed artificial trachea: in vivo bioreactor. Artif Cell Nanomed B 46(3):S1131-S1140

149. Antoniac I, Popescu D, Zapciu A, Antoniac A, Miculescu F, Moldovan H (2019) Magnesium filled polylactic acid (PLA) material for filament based 3D printing. Materials 12(5):719

150. Varga P, Lorinczy D, Toth L, Pentek A, Nyitrai M, Maroti P (2019) Novel PLA-CaCO3 composites in additive manufacturing of upper limb casts and orthotics-a feasibility study. Mater Res Express 6(4):045317

151. Khoo ZX, Mei Teoh JE, Liu Y, Kai Chua C, Yang S, An J, Leong KF, Yeong WY (2015) 3D printing of smart materials: a review on recent progresses in $4 \mathrm{D}$ printing. Virtual Phys Prototyp 10(3):103-122

152. Ghilan A, Chiriac AP, Neamtu I, Nita LE (2019) Magnetic polymeric nanocomposites. In: Vasile C (ed). Polymeric nanomaterials in nanotherapeutics

153. Karimi M, Sahandi Zangabad P, Ghasemi A, Amiri M, Bahrami M, Malekzad H (2016) Temperature-responsive smart nanocarriers for delivery of therapeutic agents: applications and recent advances. ACS Appl Mater Interfaces 8(33):21107-21133

154. Baker A, Bates S, Llewellyn-Jones T, Valori L, Dicker M, Trask R (2019) 4D printing with robust thermoplastic polyurethane hydrogel-elastomer trilayers. Mater Des 163:107544
155. Yang C, Boorugu M, Dopp A, Ren J, Martin R, Han D (2019) $4 \mathrm{D}$ printing reconfigurable, deployable and mechanically tunable metamaterials. Mater Horiz 6:1244-1250

156. Nistor M, Chiriac AP, Vasile C, Verestiuc L, Nita LE (2011) Synthesis of hydrogels based on poly(NIPAM) inserted into collagen sponge. Colloids Surf B 87(2):382-390

157. Han D, Lu Z, Chester S, Lee H (2018) Micro 3D printing of a temperature-responsive hydrogel using projection microstereolithography. Sci Rep. 8(1)

158. Bakarich S, Gorkin R, Panhuis M, Spinks G (2015) 4D printing with mechanically robust, thermally actuating hydrogels. Macromol Rapid Commun 36(12):1211-1217

159. Liu J, Erol O, Pantula A, Liu W, Jiang Z, Kobayashi K (2019) Dual-gel 4D printing of bioinspired tubes. ACS Appl Mater Interfaces 11(8):8492-8498

160. Gao B, Yang Q, Zhao X, Jin G, Ma Y, Xu F (2016) 4D bioprinting for biomedical applications. Trends Biotechnol 34(9):746-756

161. Mulakkal M, Trask R, Ting V, Seddon A (2018) Responsive cellulose-hydrogel composite ink for 4D printing. Mat Des 160:108-118

162. Lv C, Xia H, Shi Q, Wang G, Wang Y, Chen Q (2017) Sensitively humidity-driven actuator based on photopolymerizable PEG-DA films. Adv Mater Interfaces 4(9):1601002

163. Naficy S, Gately R, Gorkin R, Xin H, Spinks G (2016) 4D printing of reversible shape morphing hydrogel structures. Macromol Mater Eng 302(1):1600212

164. Kuksenok O, Balazs A (2016) Stimuli-responsive behaviour of composites integrating thermo-responsive gels with photoresponsive fibers. Mater Horizons 3(1):53-62

165. Zhu P, Yang W, Wang R, Gao S, Li B, Li Q (2018) 4D printing of complex structures with a fast response time to magnetic stimulus. ACS Appl Mater Interfaces 10(42):36435-36442

166. McCracken J, Rauzan B, Kjellman J, Su H, Rogers S, Nuzzo R (2019) Ionic hydrogels with biomimetic 4D-printed mechanical gradients: models for soft-bodied aquatic organisms. Adv Funct Mater. 1806723

167. Wei H, Zhang Q, Yao Y, Liu L, Liu Y, Leng J (2016) Direct-write fabrication of $4 \mathrm{D}$ active shape-changing structures based on a shape memory polymer and Its nanocomposite. ACS Appl Mater Interfaces 9(1):876-883

168. Jamróz W, Kurek M, Łyszczarz E, Szafraniec J, Knapik-Kowalczuk J, Syrek K (2017) 3D printed orodispersible films with Aripiprazole. Int J Pharm 533(2):413-420

169. Norman J, Madurawe R, Moore C, Khan M, Khairuzzaman A (2017) A new chapter in pharmaceutical manufacturing: 3D-printed drug products. Adv Drug Deliv Rev 108:39-50

170. Fu J, Yu X, Jin Y (2018) 3D printing of vaginal rings with personalized shapes for controlled release of progesterone. Int $\mathrm{J}$ Pharm 539(1-2):75-82

171. Ehtezazi T, Algellay M, Islam Y, Roberts M, Dempster N, Sarker S (2018) The application of 3D printing in the formulation of multilayered fast dissolving oral films. J Pharm Sci 107(4):1076-1085

172. Kotta S, Nair A, Alsabeelah N (2019) 3D printing technology in drug delivery: recent progress and application. Curr Pharm Des 24(42):5039-5048

173. Maulvi FA, Shah MJ, Solanki BS, Patel AS, Soni TG (2017) Application of 3D printing technology in the development of novel drug delivery systems. Int J Drug Dev Res 9:44-49

174. Hsiao W, Lorber B, Reitsamer H, Khinast J (2017) 3D printing of oral drugs: a new reality or hype? Expert Opin Drug Deliv 15(1):1-4

175. Pravin S, Sudhir A (2018) Integration of 3D printing with dosage forms: a new perspective for modern healthcare. Biomed Pharmacother 107:146-154 
176. Lim S, Kathuria H, Tan J, Kang L (2018) 3D printed drug delivery and testing systems - a passing fad or the future? Adv Drug Deliv Rev 132:139-168

177. Wang J, Zheng H, Chang M, Ahmad Z, Li J (2017) Preparation of active 3D film patches via aligned fiber electrohydrodynamic (EHD) printing. Sci Rep. 7(1)

178. Pere C, Economidou S, Lall G, Ziraud C, Boateng J, Alexander B (2018) 3D printed microneedles for insulin skin delivery. Int J Pharm 544(2):425-432

179. Luzuriaga M, Berry D, Reagan J, Smaldone R, Gassensmith J (2018) Biodegradable 3D printed polymer microneedles for transdermal drug delivery. Lab Chip 18(8):1223-1230

180. Malachowski K, Breger J, Kwag H, Wang M, Fisher J, Selaru F (2014) Stimuli-responsive theragrippers for chemomechanical controlled release. Angew Chem 126(31):8183-8187

181. Kim T, Lee Y (2018) Shape transformable bifurcated stents. Sci Rep. 8(1)

182. Nam H, Seo C, Joo S, Kim D, Park D (2018) The application of three-dimensional printed finger splints for post hand burn patients: a case series investigation. Ann Rehabil Med 42(4):634-638

183. Zhao F, Wang J, Wang L, Chen L (2019) An approach for simulating the fitting of rigid gas-permeable contact lenses using 3D printing technology. Contact Lens Anterio 42(2):165-169

184. Gill D, Walia K, Rawat A, Bajaj D, Gupta V, Gupta A (2019) 3D modelling and printing of craniofacial implant template. Rapid Prototyp J 25(2):397-403

185. Yu N, Nguyen T, Cho Y, Kavanagh N, Ghassib I, Giannobile W (2019) Personalized scaffolding technologies for alveolar bone regenerative medicine. Orthod Craniofac Res 22(S1):69-75

186. Yi H, Choi Y, Jung J, Jang J, Song T, Chae S (2019) Three-dimensional printing of a patient-specific engineered nasal cartilage for augmentative rhinoplasty. J Tissue Eng 10:204173141882479

187. Tappa K, Jammalamadaka U, Ballard D, Bruno T, Israel M, Vemula $\mathrm{H}$ (2017) Medication eluting devices for the field of OBGYN (MEDOBGYN): 3D printed biodegradable hormone eluting constructs, a proof of concept study. Plos One 12(8):e0182929

188. Pourchet L, Thepot A, Albouy M, Courtial E, Boher A, Blum L (2016) Human skin 3D bioprinting using scaffold-free approach. Adv Healthc Mater 6(4):1601101

189. Lee J, Hong J, Jung J, Shim J, Oh J, Cho D (2014) 3D printing of composite tissue with complex shape applied to ear regeneration. Biofabrication 6(2):024103

190. Lind J, Busbee T, Valentine A, Pasqualini F, Yuan H, Yadid M (2016) Instrumented cardiac microphysiological devices via multimaterial three-dimensional printing. Nat Mater 16(3):303-308

191. Young K, Pierce J, Zuniga J (2019) Assessment of body-powered 3D printed partial finger prostheses: a case study. 3D Printing in Medicine. 5(1)

192. Alonso M, Guerrero-Beltrán EC, Ortega-Lara W (2019) Design and characterization of gelatin/PVA hydrogels reinforced with ceramics for 3D printed prosthesis. Mater Today Proc. 13: 324-331

193. Park J, Jung S, Lee C, Ban M, Lee S, Kim H (2019) A 3D-printed polycaprolac-tone/ $\beta$-tricalcium phosphate mandibular prosthesis: a pilot animal study. Laryngoscope

194. Xu C, Lee W, Dai G, Yi Hong (2018) Highly Elastic Biodegradable Single-Network Hydrogel for Cell Printing. ACS Appl Mater Interfaces 10:9969-9979

195. Manzanares Palenzuela C, Pumera M (2018) (Bio)Analytical chemistry enabled by 3D printing: Sensors and biosensors. TrAC Trends Anal Chem 103:110-118

196. Chae M, Rozen W, McMenamin P, Findlay M, Spychal R, Hunter-Smith D (2015) Emerging applications of bedside 3D printing in plastic surgery. Front Surg. 2(25)
197. Javaid M, Haleem A (2018) Additive manufacturing applications in medical cases: a literature based review. Alexandria Med J 54(4):411-422

198. Zein N, Hanouneh I, Bishop P, Samaan M, Eghtesad B, Quintini C (2013) Three-dimensional print of a liver for preoperative planning in living donor liver transplantation. Liver Transpl 19(12):1304-1310

199. Cheung C, Looi T, Lendvay T, Drake J, Farhat W (2014) Use of 3-dimensional printing technology and silicone modeling in surgical simulation: development and face validation in pediatric laparoscopic pyeloplasty. J Surg Educ 71(5):762-767

200. Marks M, Alexander A, Matsumoto J (2017) Creating three dimensional models of Alzheimer's disease. 3D Print Med 3(1):13

201. Dimiduk DM, Holm EA, Niezgoda SR (2018) Perspectives on the impact of machine learning, deep learning, and artificial intelligence on materials, processes, and structures engineering. Integr Mater Manuf Innov 7:157-172

202. Zhang Y, Ling C (2018) A strategy to apply machine learning to small datasets in materials science. Comput Mater 4:25

203. Seko A, Hayashi H, Nakayama K, Takahashi A, Tanaka I (2017) Representation of compounds for machine-learning prediction of physical properties. Phys Rev B 95:144110

204. Medasani B (2016) Predicting defect behavior in B2 intermetallics by merging ab initio modeling and machine learning. npj Comput Mater 2:1

205. Jong MD (2016) A statistical learning framework for materials science: application to elastic moduli of k-nary inorganic polycrystalline compounds. Sci Rep 6:34256

206. Legrain F, Carrete J, Roekeghem A, Curtarolo S, Mingo N (2017) How chemical composition alone can predict vibrational free energies and entropies of solids. Chem Mater 29:6220-6227

207. Monnodi-Kanakkithodi A, Huan TD, Ramprasad R (2017) Mining materials design rules from data: the example of polymer dielectrics. Chem Mater 29:9901-9010

208. Sendek AD (2017) Holistic computational structure screening of more than 12,000 candidates for solid lithium-ion conductor materials. Energy Environ Sci 10:306-320

209. Raccuglia P (2016) Machine-learning-assisted materials discovery using failed experiments. Nature 553:73-77

210. Xue D (2015) Accelerated search for materials with targeted properties by adaptive design. Nat Commun 7:11241

211. Baumann FW, Sekulla A, Hassler M, Himpel B (2018) Trends of machine learning in additive manufacturing. Int J Rapid Manufacturing. 7(4)

212. Alabi MO, Nixon K, Botef I (2018) A survey on recent applications of machine learning with big data in additive manufacturing industry. Am J Eng Appl Sci 11(3):1114-1124

213. Athmaja S, Hanumanthappa M, Vasantha Kavitha A (2017) Survey of machine learning algorithms for big data analytics. International Conference on Innovations in Information, Embedded and Communication Systems (ICIIECS)

214. Ward L, Agrawal A, Choudhary A, Wolverton C (2016) A general-purpose machine learning framework for predicting properties of inorganic materials. NPJ Comput Mater 2:16028

215. Correa-Baena J-P, Hippalgaonkar K, van Duren J, Jaffer S, Chandrasekhar VR, Stevanovic V, Buonassisi T (2018) Accelerating materials development via automation, machine learning, and high-performance computing. Joule 2(8):1410-1420

216. Liu Y, Zhao T, Ju W, Shi S (2017) Materials discovery and design using machine learning. Journal of Materiomics 3(3):159-177

217. Gupta JK, Adams DJ, Berry NG (2016) Will it gel? Successful computational prediction of peptide gelators using physicochemical properties and molecular fingerprints. Chem Sci 7(7):4713-4719 
218. Tallorin L, Wang J, Kim WE, Sahu S, Kosa NM, Yang P, Gianneschi NC (2018) Discovering de novo peptide substrates for enzymes using machine learning. Nat Commun. 9(1)

219. https://mrsec.uchicago.edu/mat_summit

220. De Pablo JJ, Jackson NE, Webb MA, Chen LQ, Moore JE, Morgan D, Zhao JC (2019) New frontiers for the materials genome initiative. Npj Computat Mater. 5(1)

221. McIlroy C, Olmsted PD (2016) Deformation of an amorphous polymer during the fused-filament-fabrication method for additive manufacturing. J Rheol 61:379

222. Arora A (2016) Broadly accessible self-consistent field theory for block polymer materials discovery. Macromolecules 49:4675-4690

223. Webb MA (2015) Systematic computational and experimental investigation of lithium-ion transport mechanisms in polyesterbased polymer electrolytes. ACS Cent Sci 1:198-205

224. Zhu JB (2018) A synthetic polymer system with repeatable chemical recyclability. Science 360:398-403

225. Alsbaiee A (2016) Rapid removal of organic micropollutants from water by a porous $\beta$-cyclodextrin polymer. Nature 529:190-194
226. Gao J (2017) Bipolar electrode array embedded in a polymer light-emitting electrochemical cell. ACS Appl Mater Interfaces 9:32405-32410

227. Gonzalez-Henriquez CM, Sarabia-Vallejos MA, Rodriguez Hernandez J (2019) Polymers for additive manufacturing and 4D-printing: materials, methodologies, and biomedical applications. Prog Polym Sci. 57-116

228. Yuan S, Shen F, Chua CK, Zhou K (2019) Polymeric composites for powder-based additive manufacturing: materials and applications. Prog Polym Sci 91:141-168

229. Ren K, Hu M, Zhang H, Li B, Lei W, Chen J, Ji J (2019) Layerby-layer assembly as a robust method to construct extracellular matrix mimic surfaces to modulate cell behavior. Prog Polym Sci 92:1-34

Publisher's Note Springer Nature remains neutral with regard to jurisdictional claims in published maps and institutional affiliations. 